\title{
Fine-mapping and cross-validation of QTLs linked to fatty acid composition in multiple independent interspecific crosses of oil palm
}

Ngoot-Chin Ting ${ }^{1,3+}$, Zulkifli Yaakub ${ }^{1+}$, Katialisa Kamaruddin ${ }^{1 \dagger}$, Sean Mayes ${ }^{2}$, Festo Massawe ${ }^{3}$, Ravigadevi Sambanthamurthi ${ }^{1}$, Johannes Jansen ${ }^{4}$, Leslie Eng Ti Low ${ }^{1}$, Maizura Ithnin ${ }^{1}$, Ahmad Kushairi ${ }^{1}$, Xaviar Arulandoo ${ }^{5}$, Rozana Rosli ${ }^{1}$, Kuang-Lim Chan ${ }^{1}$, Nadzirah Amiruddin', Kandha Sritharan ${ }^{5}$, Chin Ching Lim", Rajanaidu Nookiah", Mohd Din Amiruddin ${ }^{1}$ and Rajinder Singh ${ }^{1 *}$

\begin{abstract}
Background: The commercial oil palm (Elaeis guineensis Jacq.) produces a mesocarp oil (commonly called 'palm oil') with approximately equal proportions of saturated and unsaturated fatty acids (FAs). An increase in unsaturated FAs content or iodine value (IV) as a measure of the degree of unsaturation would help to open up new markets for the oil. One way to manipulate the fatty acid composition (FAC) in palm oil is through introgression of favourable alleles from the American oil palm, E. oleifera, which has a more unsaturated oil.

Results: In this study, a segregating E. oleifera x E. guineensis (OxG) hybrid population for FAC is used to identify quantitative trait loci (QTLs) linked to IV and various FAs. QTL analysis revealed 10 major and two putative QTLs for IV and six FAs, C14:0, C16:0, C16:1, C18:0, C18:1 and C18:2 distributed across six linkage groups (LGs), OT1, T2, T3, OT4, OT6 and T9. The major QTLs for IV and C16:0 on LGOT1 explained 60.0 - 69.0\% of the phenotypic trait variation and were validated in two independent $\mathrm{BC}_{2}$ populations. The genomic interval contains several key structural genes in the FA and oil biosynthesis pathways such as PATE/FATB, HIBCH, BASS2, LACS4 and DGAT1 and also a relevant transcription factor (TF), WRI1. The literature suggests that some of these genes can exhibit pleiotropic effects in the regulatory networks of these traits. Using the whole genome sequence data, markers tightly linked to the candidate genes were also developed. Clustering trait values according to the allelic forms of these candidate markers revealed significant differences in the IV and FAs of the palms in the mapping and validation crosses.
\end{abstract}

Conclusions: The candidate gene approach described and exploited here is useful to identify the potential causal genes linked to FAC and can be adopted for marker-assisted selection (MAS) in oil palm.

Keywords: Elaeis guineensis, Elaeis oleifera, Backcross-two (BC2), lodine value (IV), Palmitic acid (C16:0), Oleic acid (C18:1)

\footnotetext{
* Correspondence: rajinder@mpob.gov.my

${ }^{\dagger}$ Equal contributors

'Malaysian Palm Oil Board (MPOB), P.O. Box 10620, 50720 Kuala Lumpur,

Malaysia

Full list of author information is available at the end of the article
}

\section{Biomed Central}

(c) 2016 Ting et al. Open Access This article is distributed under the terms of the Creative Commons Attribution 4.0 International License (http://creativecommons.org/licenses/by/4.0/), which permits unrestricted use, distribution, and reproduction in any medium, provided you give appropriate credit to the original author(s) and the source, provide a link to the Creative Commons license, and indicate if changes were made. The Creative Commons Public Domain Dedication waiver (http://creativecommons.org/publicdomain/zero/1.0/) applies to the data made available in this article, unless otherwise stated. 


\section{Background}

The African oil palm (Elaeis guineensis Jacq.) is the major oil crop in the world today $[1,2]$. The wide range of applications (80.0-85.0\%) for mesocarp oil is due to its FAC which is suitable for making common consumable products (e.g. cooking oil, butters and margarine), pharmaceuticals and animal feedstocks. In addition, palm oil has industrial applications, e.g. making biodiesel, oleochemicals, cosmetics and textiles.

Palm oil has roughly equal proportions of saturated and unsaturated FAs. The saturated FAs are palmitic (C16:0, $44.0 \%)$, stearic (C18:0, $4.5 \%)$, myristic (C14:0, $1.1 \%)$, arachidic (C20:0, $0.3 \%$ ) and lauric (C12:0, $0.2 \%)$. The unsaturated FAs include $39.2 \%$ oleic (C18:1), $10.1 \%$ linoleic (C18:2), $0.3 \%$ linolenic (C18:3) and $0.1 \%$ palmitoleic (C16:1) [3, 4]. In comparison, the mesocarp oil from the American oil palm, E. oleifera, is much more unsaturated with, 58.0-68.0 \% C18:1, 14.0-20.0\% C18:2 and only 15.0-20.0\% C16:0 and 0.4-1.5 \% C18:0, as observed in the MPOB Colombian germplasm collection [5]. As the current world demand is for less saturated edible oils, it would be advantageous if the $E$. guineensis oil can be selected to have a composition closer to E. oleifera oil [6, 7].

The desirable FAC in Colombian E. oleifera oil makes the palm an ideal material for introgression into elite $E$. guineensis such as the MPOB Nigerian germplasm (T128), which is already known for its higher unsaturated oil content $[8,9]$. The T128 germplasm has been distributed as a high IV material [MPOB's PORIM Series 2 (PS2)] and extensively used in various interspecific breeding programs by the oil palm industry $[9,10]$. Therefore, it is important to capture the favourable alleles linked to high IV in the successive hybrids and backcrosses. The resulting E. oleifera $\times$ E. guineensis interspecific hybrid population was found to be segregating for IV and major FA traits which allowed for identification of QTLs linked to these traits. A number of QTLs for IV and FAC located on the T128 parental genetic map and mostly flanked by amplified fragment length polymorphism (AFLP) and restricted fragment length polymorphism (RFLP) markers were reported by Singh et al. [8]. The current study reports an extension of the work initiated by Singh et al. [8] by identifying QTLs on a higher density simple sequence repeat (SSR) and single nucleotide polymorphism (SNP)-based genetic map [11].

In plants, the FA and triacylglycerol (TAG) biosynthesis pathways occur in separate compartments. De novo FA synthesis occurs in the plastid and the growing FA chain is held by acyl carrier protein (ACP). Subsequently, acyl-ACPs are hydrolysed by acyl-ACP thioesterases and the resulting non-esterified FAs exported to the endoplasmic reticulum (ER) for assembly into TAGs
$[12,13]$. Recently, oil palm transcriptome data from developing fruits (particularly from the mesocarp tissues) were used to investigate the regulatory mechanisms of genes and transcription factors (TFs) governing the synthesis of FA and TAG $[14,15]$. The formation of FA destined for oil accumulation starts around 110 days after pollination (DAP) and reaches its peak at 120 DAP. It is during this period that TAGs begin to accumulate in the mesocarp and reach a peak at 160 DAP [14].

The transcriptome data have also opened up new avenues to develop candidate markers for FA biosynthesis genes with oil palm orthologues identified for $\beta$-ketoacylACP synthases (KASI and II), acyl-ACP thioesterases (FATA and $B$ ) and stearoyl-ACP desaturase (SAD). The data was exploited by Montoya et al. [16], where SNP markers were developed from these candidate genes and 14 of them were polymorphic and located on the $E$. oleifera $\times E$. guineensis pseudo-backcross-one $\left(\mathrm{BC}_{1}\right)$ genetic map. Among the 14 SNP markers, four located within the confidence intervals of QTLs linked to IV and FAC $[16,17]$. Taking a slightly different approach, potential candidate genes and a TF associated with biosynthesis of FA and TAG were identified in the major QTL regions revealed in this study. This was done by comparing the QTL regions (linked to FAC) to the oil palm genome assembly [18]. Markers based on these candidate genes were developed to saturate the QTL intervals. The saturated QTL regions revealed closely linked markers and, if validated across different genetic backgrounds, these markers could have utility in a MAS program. A similar approach has been applied with great success in rice and even oil palm, in identifying candidate genes linked to mapped QTLs [19, 20].

The second part of this study focused on validating the consistency of QTLs linked to IV and FAC in two independent pseudo- $\mathrm{BC}_{2}$ populations of E. guineensis $\times E$. oleifera $(\mathrm{GxO})$. The validation families were derived from different genetic backgrounds compared to the populations described by Montoya et al. [16, 17]. In addition to validating some of the previously reported QTL locations, this study revealed additional genomic regions influencing IV and FAC. Compilation of different favourable alleles of QTLs obtained from various genetic backgrounds will help to develop effective strategies for the application of MAS in an interspecific hybrid breeding program. In soybean, Wang et al. [21] described MAS for C16:0 and C18:0 through pyramiding of two to three QTLs, detected across various genetic backgrounds, exhibiting significant cumulative effects. Similarly, this study aimed to uncover a set of markers that can be used to select for favourable alleles linked to unsaturation, at least in the genetic backgrounds examined. 


\section{Methods}

\section{Mapping population}

The mapping population 'OxG' is an interspecific cross between a Colombian E. oleifera (UP1026, maternal parent) and an Nigerian E. guineensis tenera (T128, paternal parent) as reported by Singh et al. [8] and Ting et al. [11]. The population consists of 118 hybrids and was created and is maintained by United Plantations Berhad (UPB), Perak, Malaysia. Of these, eight palms were excluded from the linkage analysis due to relatively high recombination frequencies [8]. An additional two palms died and therefore, only 108 palms were used in this study.

\section{Validation crosses}

Two $\mathrm{BC}_{2}$ crosses from an independent breeding program at UPB were used to attempt to validate the QTLs detected in the OxG mapping population. The breeding approach used in creating the $\mathrm{BC}_{2}$ crosses is illustrated in Fig. 1. The first cross was between a La Mé E. guineensis (L2T, maternal parent) and a Colombian E. oleifera
(79/4.4-12/6.61, paternal parent) and is termed ' $\mathrm{GxO}$ '. The resulting $\mathrm{GxO} \mathrm{F}_{1}$ hybrid (983/2.4-43/15.90) was then backcrossed with palm T128, from the Nigerian germplasm to produce the $\mathrm{BC}_{1}$. Pollen was then obtained from a selected $\mathrm{BC}_{1}$ palm $(335 / 5.2-5 / 23.96)$ to crosspollinate two E. guineensis palms. The first E. guineensis (1084/TP51/22.32) was derived from a cross between the palm T128 and a Serdang pisifera and the second palm (320/TT113/22.32) was derived from a self-pollination of the original $\mathrm{T} 128$ palm. The two $\mathrm{BC}_{2}$ families are named Progenies '2.6-1' and '2.6-5', consisting of 74 and 80 palms, respectively. They were field planted in the year 2000. The female parent of 2.6-5 (320/TT113/22.32) died before any leaf and fruit could be sampled. Therefore, two siblings to $320 / \mathrm{TT} 113 / 22.32$ were genotyped to help with scoring and phase configuration of the markers used for the construction of genetic maps.

\section{Extraction and analysis of palm oil}

The procedures for sampling ripe fruits and extracting mesocarp oil were as described by Singh et al. [8]. The

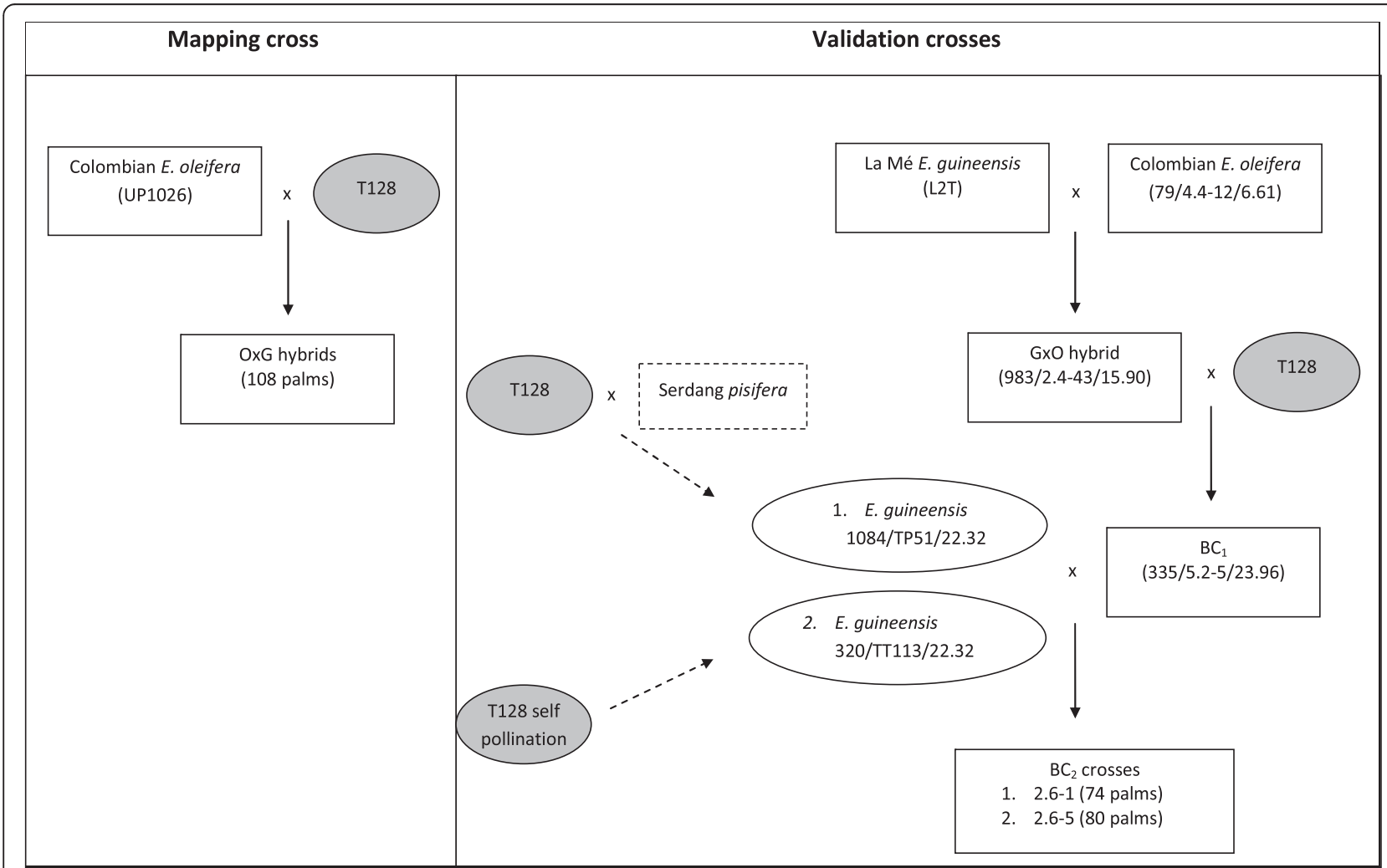

Fig. 1 The OxG mapping population and $\mathrm{BC}_{2}$ validation crosses used in this study. The 108 OxG interpecific hybrids (left) were created by crossing a maternal Colombian E. oleifera (UP1026) with a paternal palm T128 (tenera), from the Nigerian germplasm. The same T128 palm was also used in creating the $\mathrm{BC}_{2}$ validation crosses (right). The La Mé E. guineensis (L2T, maternal parent) was crossed with a Colombian E. oleifera (79/4.4-12/6.61, paternal parent) and the resulting GXO F hybrid (983/2.4-43/15.90) was then backcrossed with the T128 palm to produce the $\mathrm{BC}_{1}$. Pollen from a selected $\mathrm{BC}_{1}$ palm (335/5.2-5/23.96) was used to cross-pollinate two E. guineensis palms. The first $E$. guineensis (1084/TP51/22.32) was derived from a cross between the T128 and a Serdang pisifera and the second palm (320/TT113/22.32) was derived from a self-pollination of the T128 palm. The two $\mathrm{BC}_{2}$ families namely, 2.6-1 and 2.6-5 consisted of 74 and 80 palms, respectively 
PORIM Test Method [22] was applied to measure the IV and FAC in the palm oil.

\section{Candidate SNP markers and genetic linkage map construction}

Candidate SNP markers (designated SNPE) flanking various genes associated with FA and oil biosynthesis were mined from the P5 genome build. The oil palm SNP assay design and genotyping were performed by a service provider, Agena Bioscience, Inc. (San Deigo, California) using the iPLEX biochemistry on MassArray ${ }^{\circ}$ system [23]. A custom two-multiplexed genotyping assay was designed and optimized for a panel of 40 SNPs using the Assay Design Suite 1.0 software (Agena Bioscience, Inc. San Deigo, California). Primary PCR primers (forward and reverse) were designed to contain a common 5', 10-mer tag (ACGTTGGATG) and synthesized by IDT (Singapore and USA). The primary PCR reaction was carried out to amplify DNA fragments of approximately $100 \mathrm{bp}$ containing targeted SNPs from the good quality $\left(\mathrm{A}_{260} / \mathrm{A}_{280}\right.$ ratio $\left.>1.7\right)$ oil palm genomic DNA (20 ng/ $\mu \mathrm{l})$. The PCR conditions included an initial denaturation at $95{ }^{\circ} \mathrm{C}$ for $2 \mathrm{~min}, 45$ cycles of $95{ }^{\circ} \mathrm{C}$ denaturation $(20 \mathrm{~s}), 56{ }^{\circ} \mathrm{C}$ annealing $(30 \mathrm{~s})$ and $72{ }^{\circ} \mathrm{C}$ extension $(1 \mathrm{~min})$, and a final extension at $72{ }^{\circ} \mathrm{C}$ for $5 \mathrm{~min}$. The remaining unincorporated dNTPs in the PCR product was inactivated using shrimp alkaline phosphatase (SAP) treatment (Agena Bioscience, Inc. San Deigo, California). This was followed by an allele-specific single base primer extension reaction performed using the iPLEX Gold Reaction Kit (Agena Bioscience, Inc. San Deigo, California). Reaction cocktail containing extend primer, buffer, enzyme, and mass-modified ddNTPs (prepared following the manufacturer's protocol) was added to the primary PCR product and proceeded to extension reaction at $94{ }^{\circ} \mathrm{C}$ initial denaturation (30 s), 40 cycles of $95{ }^{\circ} \mathrm{C}$ denaturation $(5 \mathrm{~s}), 52{ }^{\circ} \mathrm{C}$ annealing $\left(5 \mathrm{~s}, 5\right.$ cycles) and $80{ }^{\circ} \mathrm{C}$ extension ( $5 \mathrm{~s}, 5$ cycles), and a final extension at $72{ }^{\circ} \mathrm{C}$ for $3 \mathrm{~min}$. The extension reaction product was desalted using the SpectroCLEAN (Agena Bioscience, Inc. San Deigo, California) resin treatment and transferred onto the SpectroCHIP Array (Agena Bioscience, Inc. San Deigo, California) for data analysis using MatrixAssisted Laser Desorption/Ionization Time-Of-Flight (MALDI-TOF) mass spectrometry. The SNP genotyping data and report were generated using the Typer 4.0 software (Agena Bioscience, Inc. San Deigo, California). The genotyping data were incorporated into the existing dataset [11] for construction of the genetic map.

Furthermore, the AFLP and RFLP markers reported by Singh et al. [8] to be flanking the QTL regions were also incorporated into the existing linkage map which was re-constructed using JoinMap 4.1 [24] as described previously [11]. The genetic maps for the two validation crosses, 2.6-1 and 2.6-5, were similarly constructed using the same set of SNP and SSR markers (except SNPE markers). Comparison of the genetic maps for OxG, 2.6-1 and 2.6-5 was carried out using MapChart $2.2[25]$.

\section{Quantitative trait loci (QTL) analyses}

In the OxG population, the QTL analysis was performed using Interval Mapping (IM), the Multiple-QTL Model (MQM) and the Kruskal-Wallis non-parametric ranking tests $(\mathrm{KW})$ with the default parameters in MapQTL 6 [26]. The $95 \%$ genome-wide LOD significance threshold for each trait was determined by the permutation test option, with 1,000 permutations. Each candidate QTL interval was further analyzed using G model (GM) [27]. The GM analysis first estimated the genome-wide background effects of markers (co-factors) from all the LGs (except the LG being analyzed) using a random effects model (ridge-regression best linear unbiased prediction, RR-BLUP). The background effects were used to correct and determine significant markers by backward elimination (screening for QTL) on each LG. Finally, the effect of each significant marker was estimated using the multiple regression coefficients. Similar QTL analysis approaches were also applied in the 2.6-1 and 2.6-5 crosses to validate the detected QTLs.

\section{Development of candidate SSR markers within QTL confidence regions}

Development of SSR markers (with nomenclature sPSc) for candidate FA genes and TF was carried out by aligning contigs and clone sequences (http:// genomsawit.mpob.gov.my) containing the SNPs and SSRs mapped in the QTL confidence intervals, using BLASTN [28]. Markers from another independent genetic map (LGDP1) [11] that localize in the QTLsyntenic regions were also included in the similarity search. Scaffold regions linked to QTL confidence intervals were extracted from the P5 genome build and searched for sequence similarity (BLASTN and BLASTX) against the NCBI databases (nt, $\mathrm{nr}$ and refseq_protein). Sequences with significant similarity (BLASTN e-value of $<1 \mathrm{e}-25$ and $95 \%$ identity over total sequence length) to genes and TFs associated with FA and TAG syntheses were selected to attempt to mine SSRs using the MIcroSAtellite identification tool (MISA) [29].

Four percent Super Fine Resolution (SFR) agarose (Amresco, USA) gel electrophoresis was used to screen for potential polymorphism of the candidate SSRs against a panel of six randomly selected OxG hybrids and the two parental palms. The informative 
SSRs were then PCR-amplified using the M13-tailed primer (5'CACGACGTTGTAAAACGAC3') approach as described by Ting et al. [30]. Fragment analysis of the PCR products was performed by a service provider at the Centre for Marker Discovery and Validation (CMDV), Malaysia using an ABI 3730XL DNA analyzer (Applied Biosystems, USA) with fluorescent dye sets comprising FAM, NED, PET, VIC and GeneScan ${ }^{\text {Th }}-500$ LIZ Size Standard. Sizing of the SSR alleles was performed using the GeneMapper 4.1 software (Applied Biosystems, USA) and genotype scoring was as described previously $[11,30]$.

\section{Results}

\section{Mapping candidate SNPs for FA genes onto the OxG genetic map}

In the OxG interspecific population, the existing paternal T128 (T) and partially integrated (OT) maps had 1,121 markers/16 LGs/1,759 cM and 899 markers/10 LGs/ 1,249 cM, respectively [11]. The two genetic maps were constructed mainly with SNP and SSR markers replacing the traditional AFLP and RFLP markers used in the earlier version (252 markers/21 LGs/1,815 cM) [8]. The new marker systems are technically more user-friendly, cheaper and give better reproducibility than the AFLP and RFLP markers. However, to anchor the previously [8] detected QTLs, the AFLP and RFLP markers flanking each QTL interval were also incorporated into this study.

An additional 40 SNPs (SNPE) were identified flanking various FA genes distributed across 22 scaffolds of the P5 genome build. Of these, seven for palmitoyl-ACP thioesterase (PATE/FATB - SNPE00431), oleoyl-CoA desaturase (FAD2 - SNPE00437), linoleoyl-CoA desaturase (FAD3 - SNPE00401), enoyl-ACP reductase (ENR1 - SNPE00415 and 00416) and stearoyl-ACP desaturase (SAD - SNPE00427 and 00434) - were polymorphic in the OxG mapping population. These candidate SNP markers were mapped onto LGs OT1, T2, OT11, OT12 and T14 (Additional file 1) and used in the subsequent QTL analysis. For the OxG mapping population, as only 10 integrated LGs (OT 1, 4, 6, 7, 8, 10, 11, 12, 13 and 15) were available, six LGs (T2, 3, 5, 9, 14 and 16) from the T128 paternal map were also included in the QTL analysis.

\section{$\mathrm{BC}_{2}$ genetic linkage maps}

In the $\mathrm{BC}_{2}$ validation crosses, two independent integrated maps with 1,755 markers/16 LGs/1,499.5 cM (unpublished) and 1,184 markers/18 LGs/1,589.7 cM [31] were constructed for the $2.6-1$ and $2.6-5$ populations, respectively. Resolution of the two genetic maps was good and the linear order of markers comparable to that in OxG with an average gap of $0.9 \mathrm{cM}(2.6-1)$ and $1.3 \mathrm{cM}(2.6-5)$. Both the high density genetic maps were used for QTL analysis.

\section{IV and FAC quantitative phenotypic data}

In the OxG cross, palm oil was obtained from $85 \mathrm{~F}_{1}$ palms and measured for IV, C14:0, C16:0, C16:1, C18:0, C18:1, C18:2 and C18:3. The remaining palms could not be sampled due to sterility issues, abortive bunches and crown disease. Also 13 palms had died before phenotyping. The present phenotypic data set includes an additional four palms to that reported by Singh et al. [8] and is summarised in Table 1. Overall, the distribution of phenotypic data was similar to that reported previously. The IV $(p=0.20)$ and major FAs, C16:0 $(p=0.05)$, C18:1 $(p=0.16)$ and C18:2 $(p=0.20)$ showed a normal distribution (Kolmogorov-Smirnov, SPSS 16.0). However, the four minor components, C14:0 $(p=0.0), C 16: 1$ $(p=0.0), \mathrm{C} 18: 0(p=0.02)$ and $\mathrm{C} 18: 3(p=0.0)$ did not follow a normal distribution, also previously observed by Montoya et al. [16]. For C18:0, the data was converted to a normal distribution $(p=0.20)$ by $\log _{10}$ transformation, but the approach did not convert $\mathrm{C} 14: 0, \mathrm{C} 16: 1$ and $\mathrm{C} 18: 3$ to a normal distribution. For these non-normally distributed traits, KW analysis was used. Correlation analysis gave similar results to those by Singh et al. [8] (Additional file 2).

For the two $\mathrm{BC}_{2}$ crosses, data were collected for 54 and 57 palms of the 2.6-1 and 2.6-5 crosses, respectively. The other palms did not bear any fruit or had died before sampling could be performed. In 2.6-1, the widest data range observed (Table 1) was for C18:1 $(40.9-57.2 \% \pm 2.9)$ and C16:0 (24.7-36.7 \% \pm 0.08$)$. All the data showed normal distributions except for IV, C14:0 and C16:1. However, $\log _{10}$ transformation (IV) and the discarding of one or two outliers (for C14:0 and C16:1) returned the distributions to normality. Outliers were identified by using a Boxplot and comparing the observed and expected mean (5\% trimmed mean, SPSS 16.0) values. Significant positive correlations were observed between C14:0 and C16:0 ( $r=0.72)$, IV and C18:1 $(r=0.51)$ and, IV and C18:2 $(r=0.51)$. Strong negative correlations $(r=-0.62$ to -0.75$)$ were observed for C16:0 and C18:1, IV and C16:0, IV and C14:0 and, C16:1 and C18:0 while, $\mathrm{C} 14: 0$ and $\mathrm{C} 18: 2, \mathrm{C} 14: 0$ and $\mathrm{C} 18: 1$ and, C18:1 and C18:2 showed moderate negative correlations of -0.38 to -0.48 (Additional file 3).

In 2.6-5, C18:1 and C16:0 also showed the widest data distribution of $37.6-54.5 \%(\mathrm{SD}=3.7)$ and $26.9-41.7 \%$ $(\mathrm{SD}=2.9)$, respectively. The phenotypic data (except for C14:0, C16:1 and C18:3) demonstrated a normal distribution. For C14:0 and C16:1, normality was improved after removing one outlier. The phenotypes IV and C18:2, C14:0 and C16:0, C14:0 and C18:3 and, C14:0 and C16:1, showed moderate correlations $(r=0.42-0.55)$ while, negative correlations were obtained for IV and C16:0, C16:0 and C18:1, C18:1 and C18:2, C14:0 and C18:1 and, C16:1 and C18:0 (Additional file 4). 
Table 1 Summary of phenotypic data in the OxG mapping population and two $\mathrm{BC}_{2}$ (2.6-1 and 2.6-5) validation crosses

\begin{tabular}{|c|c|c|c|c|c|c|c|c|c|}
\hline \multirow[t]{2}{*}{ Trait } & \multicolumn{3}{|l|}{ OxG $(n=85)$} & \multicolumn{3}{|l|}{$2.6-1(n=54)$} & \multicolumn{3}{|l|}{$2.6-5(n=57)$} \\
\hline & Mean $(\% \pm S D)$ & Variance & Range (\%) & Mean $(\% \pm S D)$ & Variance & Range (\%) & Mean $(\% \pm S D)$ & Variance & Range (\%) \\
\hline lodine value (IV) & $70.98( \pm 2.88)$ & 8.28 & $65.25-77.33$ & $65.13( \pm 2.55)$ & 6.51 & $60.19-69.86$ & $63.44( \pm 3.24)$ & 10.46 & $57.12-71.60$ \\
\hline Myristic acid (C14:0) & $0.29( \pm 0.09)$ & 0.01 & $0.14-0.55$ & $0.27( \pm 0.08)$ & 0.007 & $0.14-0.49$ & $0.43( \pm 0.14)$ & 0.02 & $0.17-0.75$ \\
\hline Palmitic acid (C16:0) & $29.22( \pm 3.07)$ & 9.45 & $22.25-34.33$ & $31.06( \pm 0.08)$ & 6.08 & $24.73-36.68$ & $35.29( \pm 2.86)$ & 8.15 & $26.85-41.69$ \\
\hline Palmitoleic acid (C16:1) & $0.43( \pm 0.14)$ & 0.02 & $0.20-0.83$ & $0.12( \pm 0.02)$ & 0.000 & $0.07-0.16$ & $0.18( \pm 0.06)$ & 0.003 & $0.08-0.34$ \\
\hline Stearic acid (C18:0) & $2.08( \pm 0.32)$ & 0.10 & $1.50-3.10$ & $6.15( \pm 1.31)$ & 1.73 & $3.29-9.43$ & $3.79( \pm 0.93)$ & 0.86 & $2.11-6.48$ \\
\hline Oleic acid (C18:1) & $53.96( \pm 3.19)$ & 10.20 & $48.20-61.45$ & $48.61( \pm 2.87)$ & 8.25 & $40.92-57.18$ & $47.08( \pm 3.68)$ & 13.55 & $37.58-54.48$ \\
\hline Linoleic acid (C18:2) & $12.76( \pm 0.91)$ & 0.82 & $10.45-15.15$ & $12.86( \pm 1.41)$ & 1.98 & $9.60-16.29$ & $12.67( \pm 2.07)$ & 4.27 & $8.15-17.65$ \\
\hline Linolenic acid (C18:3) & $0.50( \pm 0.08)$ & 0.01 & $0.40-0.65$ & $0.36( \pm 0.06)$ & 0.004 & $0.16-0.49$ & $0.22( \pm 0.15)$ & 0.02 & $0-0.53$ \\
\hline
\end{tabular}

Means (\%), ranges and variances measured for iodine value and various fatty acid contents in palm oil

\section{OxG: QTLs linked to IV and FAC}

This study aimed to identify the QTLs linked to IV and FAC in the improved SNP and SSR-genetic map of the OxG cross [11]. Ten genome-wide significant QTLs and two putative QTLs (at chromosome-wide threshold levels) linked to IV, C14:0, C16:0, C16:1, C18:0, C18:1 and C18:2 were identified on LGs OT1, T2, T3, OT4, OT6 and T9 using a combined QTL detection method IM, MQM and KW. Only markers or regions consistently linked to the specific QTL using all three approaches were considered to be significant QTL. Subsequently, GM was used to estimate the effects of closely flanked markers using multiple regression coefficients after backward elimination and adjustment for the background marker effects [27].

On the improved LGOT1 (labelled Group 1 previously), three major QTLs (for IV, C16:0 and C18:1) and two minor QTLs (for C14:0 and C18:0) were revealed in the same map interval previously reported between markers pOP-CB00075a and EAGG/MCAT-198 (Fig. 2, a). On the current LGOT1, the significance interval between the two markers (a $12 \mathrm{cM}$ gap was reported previously) was filled by 12 SNPs and three SSRs. Of these, six SNP markers, including a PATE candidate SNP (SNPM04501, SNPM00967, SNPM00144, SNPM01034, SNPM00150 and SNPE00431), were within the QTL confidence interval (Fig. 2). This genomic region was of interest and further investigation was carried out with the additional results presented below in the 'Fine-mapping of the QTLs on LGOT1' section.

For group 9 (Group 15 in [8]), three genome-wide significant QTLs for C14:0, C16:1 and C18:0 were identified and the interval was flanked by markers EAAG/MCAT-221 and P4T8I, as reported previously. The current map position for EAAG/MCAT-221 was determined using a less stringent mapping parameter (Fig. 2, b). The interval between EAAG/MCAT-221 and P4T8I contained three SNP markers, which reduced the gap to $2.8 \mathrm{cM} /$ markers from the previous
5.8 cM. For C16:1 and C18:0, the QTL peak colocalized with markers SNPM00922 and SNPM00331 at map position $22.0 \mathrm{cM}$. Using GM, the marker effect was estimated to be $0.08 \%(p=0.0)$ and $-0.03 \%$ $(p=0.0000006)$ for $\mathrm{C} 16: 1$ and $\mathrm{C} 18: 0$, respectively. When the genotypes of the two markers were analysed, the $a b$ and $a a$ profiles showed significant differences $(p<0.05 T$-test, SPSS 16.0) for C16:1 and C18:0 contents in the OxG hybrids (Fig. 3, a \& b). For SNPM00922 (SNPM00331), the homozygous aa $(a b)$ genotype showed an average $0.53 \%(\mathrm{SD}=0.1)$ for $\mathrm{C} 16: 1$ and $1.91 \%(\mathrm{SD}=0.2)$ for $\mathrm{C} 18: 0$ content which differed from the heterozygous $a b(a a)$ genotypes $(0.35 \% \pm 0.07$ for $\mathrm{C} 16: 1$ and $2.20 \% \pm 0.3$ for C18:0). However, for $\mathrm{C} 14: 0$, the closest marker was SNPM00343 (located at $17.2 \mathrm{cM}$ ) with a minor effect of $-0.03 \%(p=0.0)$ and which also showed a significant difference in C14:0 content between the $a a$ $(0.25 \% \pm 0.07)$ and $a b \quad(0.34 \% \pm 0.1)$ genotypes (Fig. 3, c).

For LGOT4 (similar to Group 3 in [8]) QTL was detected for C18:0 in the 158.4-176.5 cM interval flanked by SNPM02160 and SNPM00121 (Fig. 2, c). The closest marker SNPM00121 at $165.1 \mathrm{cM}$, had a positive effect of $0.02 \%(p=0.0)$ on the trait, as estimated by GM. On LGT2 (Group 8 in the previous study), three markers (SNPM04410, SNPM01906 and SNPM04068) showed significant association with C14:0 (Fig. 2, d). These markers, co-localized with the QTL peak at map position $61.2 \mathrm{cM}$, were found at a distance $36.5 \mathrm{cM}$ from the previously detected QTL (indicated by EACA/MCAA-270 and EAAC/ MCAC-133). In addition, two putative QTLs for C18:2 were detected on LGs T3 (46.9-65.2 cM) and OT6 (38.9-54.5 cM) (Fig. 2, e \& f). The putative (chromosome-wide) QTLs were considered in this case as the regions concerned also explained similar QTLs in other studies (described below). A summary of the QTL results is presented in Table 2 . 

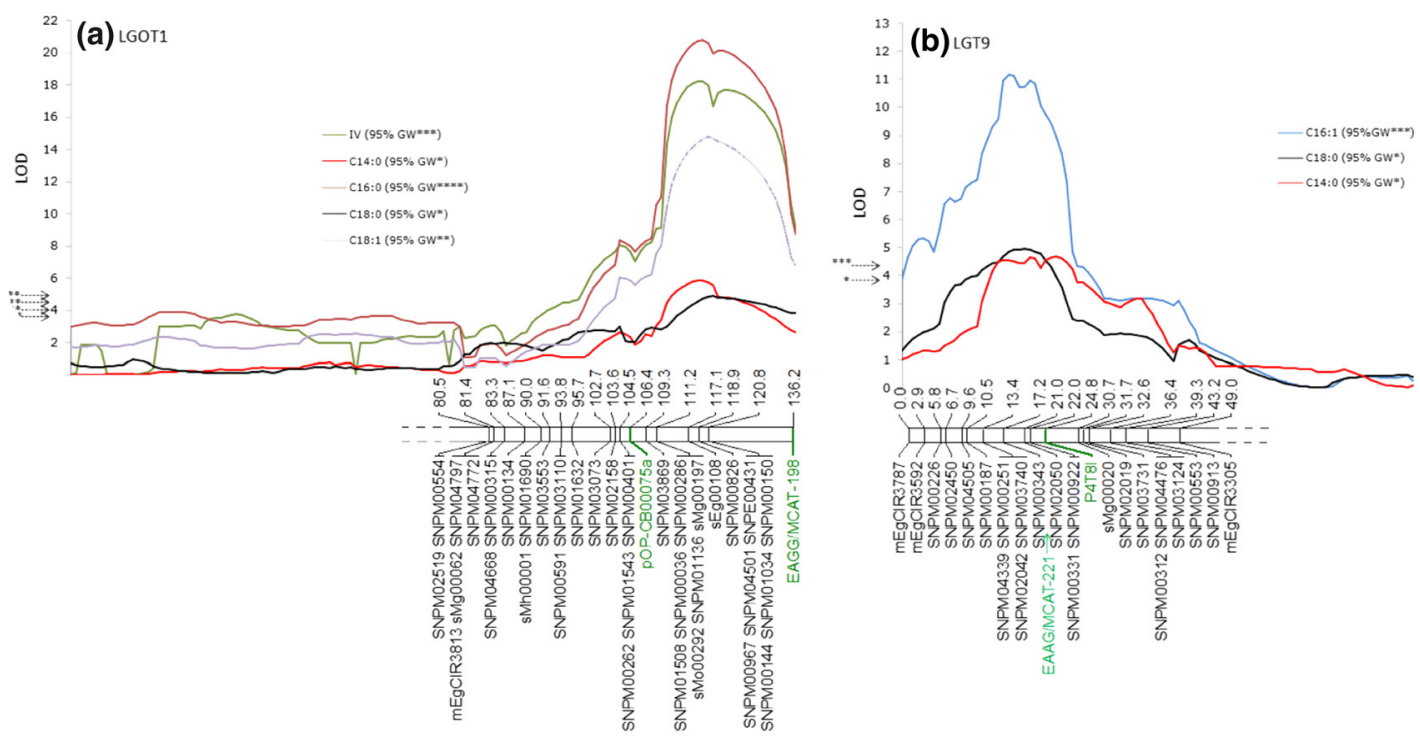

${ }^{6}$ (c) ${ }_{\mathrm{LGOT}}$
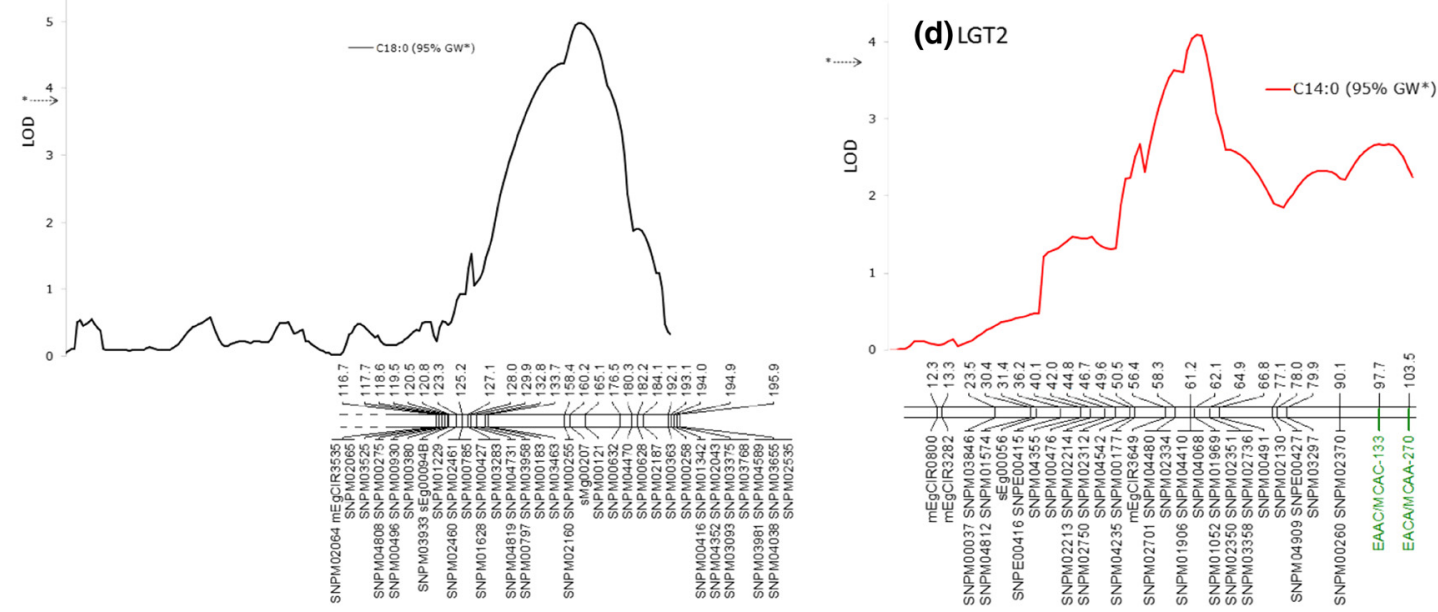

${ }^{3}$ (e) LGT3
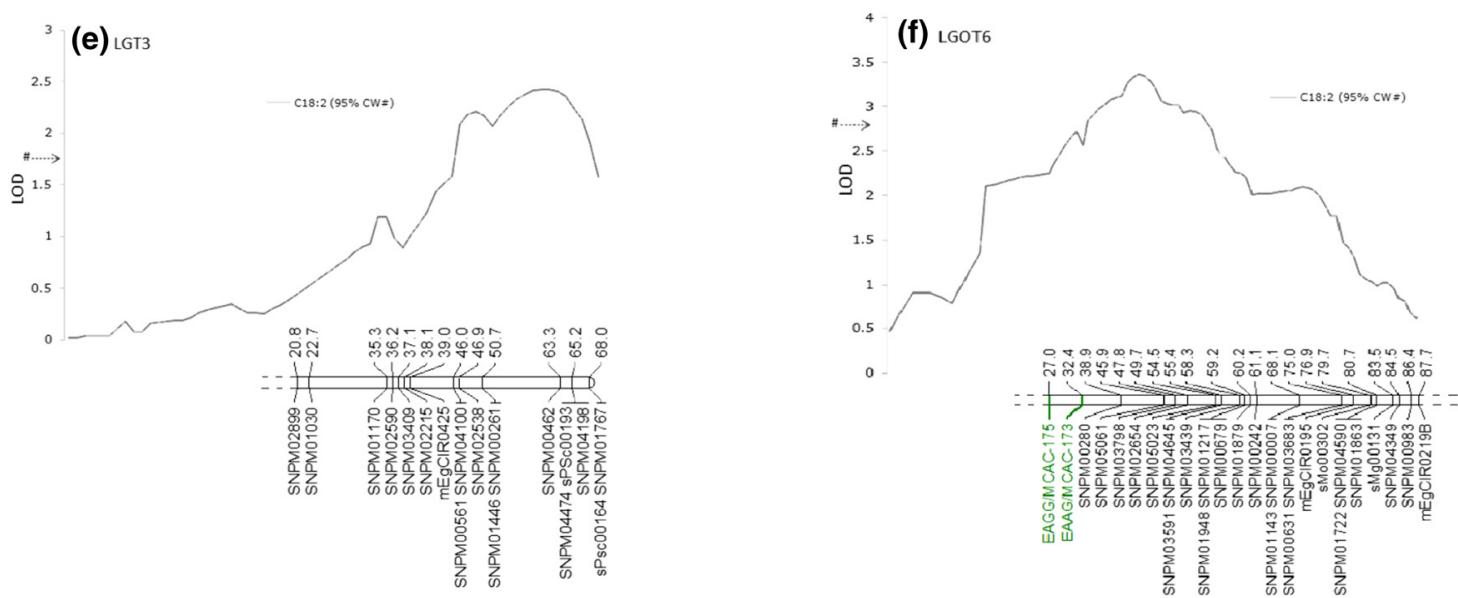

Fig. 2 QTL profiles linked to IV and FAC on the improved genetic linkage map of OxG. The graphs (a - $\mathbf{f}$ ) present QTLs (represented by different colour lines) significant at $95 \%$ genome-wide (GW) and chromosome-wide (CW) thresholds in linkage groups (LGs) OT1, T9, OT4, T2, T3 and OT6 

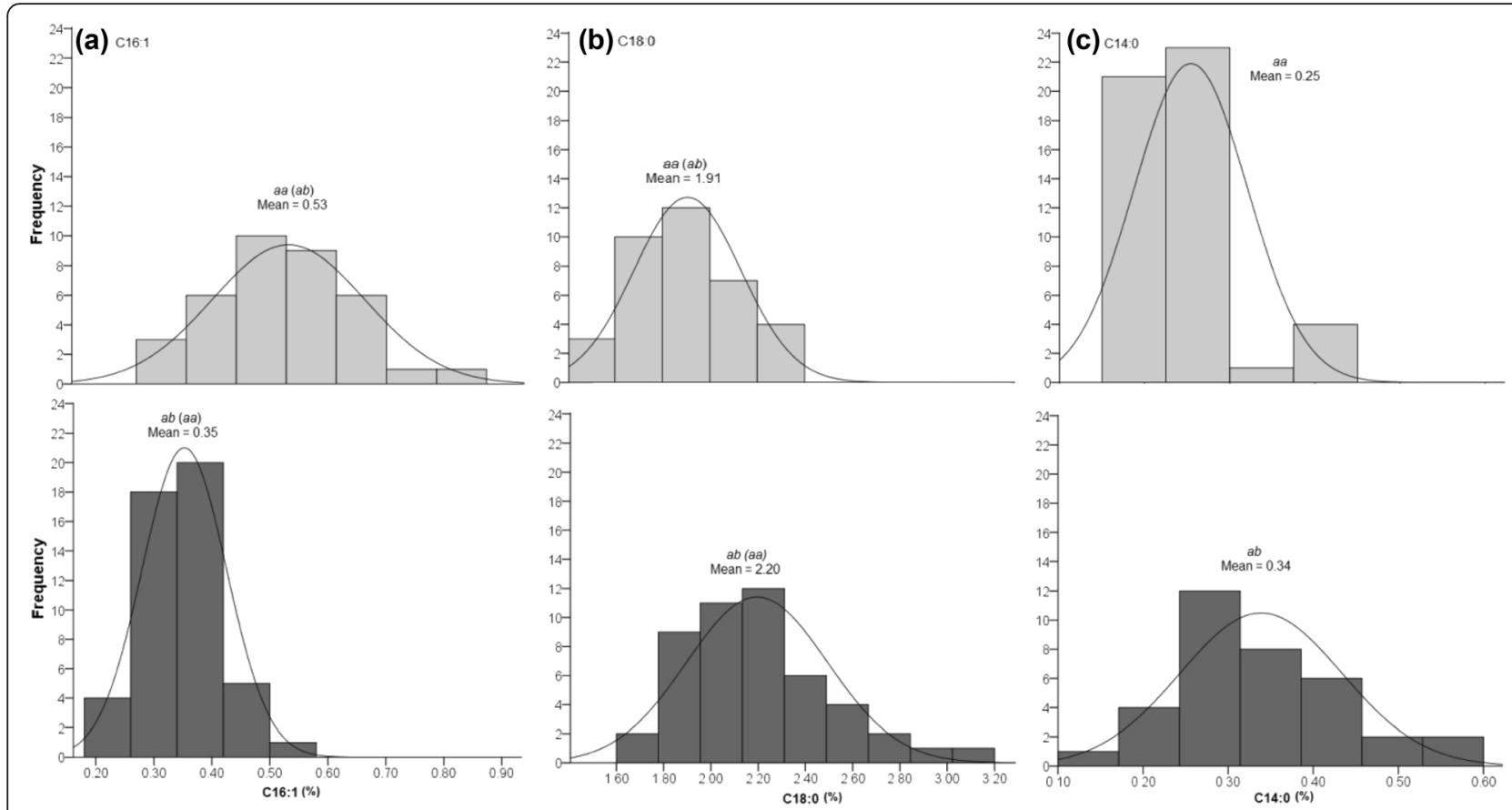

Fig. 3 Distribution of phenotypes categorized based on the genotypes of the closest markers linked to the observed QTLs in LGT9. The upper panel (light grey) is of hybrids with genotype $a b(a)$ while the lower panel (dark grey) shows the phenotypes observed in genotype $a a(a b)$ in SNPM00331 (SNPM00922) for C16:1 (a) and C18:0 (b) and, SNPM00343 for C14:0 (c)

\section{Fine-mapping of the QTLs on LGOT1}

The map interval 106.4-136.2 cM (between pOPCB00075a and EAGG/MCAT-198) on LGOT1, revealed multiple QTLs (IV, C14:0, C16:0, C18:0 and C18:1) with a relatively large proportion of phenotypic variation explained (30.5-69.4\%) and was of particular interest. Admittedly, the phenotypic variation could have been overestimated due to the limited size of the mapping family, leading to a Beavis effect $[32,33]$. The markers in this region were mapped to the P5 genome build [18]. To improve the efficiency of finding the QTL corresponding region in the genome build, additional markers that fit into the region were also obtained from an independent E. guineensis map (LGDP1) [11]. This resulted in 29 markers (including 13 SNPs from LGDP1) mapping to scaffolds p5_sc00001 and p5_sc00104 with high identities (95-100\%) and e-values $0-1 \mathrm{e}-167$. The total physical coverage of the QTL interval on p5_sc00001 (total 22,100,610 bp) and p5_sc00104 (total 2,594,271 bp) were $6,127,438$ bp $(27.7 \%)$ and 1,689,644 bp (65.1\%), respectively.

The BLAST results for the QTL corresponding region identified significant similarity to one TF and a number of genes associated with the FA and TAG biosynthesis pathways $[14,15]$. This included diacylglycerol acyltransferase (DGAT1) and long chain acyl-CoA synthetase (LACS4) in p5_sc00001. In p5_sc00104, sodium/metabolite cotransporter (BASS2), palmitoyl-ACP thioesterase
(PATE/FATB), 3-hydroxyisobutyryl-CoA hydrolase-like protein $3(H I B C H)$ and AP2-like ethylene-responsive TF (WRI1) were found. For fine mapping the QTL confidence interval, SSRs (with nomenclature sPSc) were mined and developed from the candidate gene introns (12 SSRs) and regions (11 SSRs) flanked at 1,096-25,202 bp before the 5' start codon (upstream) and 351-4,095 bp downstream (after the 3' stop codon) of the genes. In addition, six SSRs were developed specifically to fill in the gaps in the identified interval and therefore were not located near to any candidate gene. Of the 29 developed candidate SSRs, 12 were polymorphic and mapped back to the QTL interval on LGOT1. Unfortunately, five SSRs for DGAT1 were not polymorphic and could not be mapped onto LGOT1. Refined QTL intervals for IV, C14:0, C16:0, C18:0 and C18:1 as well as the map positions of the candidate genes and TF are illustrated in Fig. 4.

After fine-mapping with candidate markers, slight increases in the LOD scores were observed for markers in the QTL intervals. For IV, significant QTL with LODs 6.3-17.4 were revealed in the $113-161.8 \mathrm{cM}$ interval on LGOT1. Two candidate genes, HIBCH and PATE/FATB, together with three candidate SSRs (PA5_OSSR, PA3_oSSR and sPSc00328) and six existing SNPs (SNPM04501, SNPM00967, SNPM00144, SNPM01034, SNPM00150 and SNPE00431) co-localized directly with the QTL peak (at $149.6 \mathrm{cM}$ ). No recombination event was observed between the nine markers, possibly due to the limited 
Table 2 QTLs linked to iodine value (IV) and fatty acid composition (FAC) in the OxG interspecific mapping population. QTLs identified using Interval Mapping (IM), the Multiple-QTL Model (MQM), the Kruskal-Wallis non-parametric tests (KW) and G Model (GM)

\begin{tabular}{|c|c|c|c|c|c|c|c|c|c|c|c|}
\hline \multirow[t]{2}{*}{ Trait } & \multicolumn{5}{|l|}{ IM } & \multicolumn{2}{|c|}{ MQM } & \multicolumn{2}{|l|}{$\mathrm{KW}$} & \multicolumn{2}{|l|}{ GM } \\
\hline & $\begin{array}{l}\text { QTL interval } \\
\text { (cM) }\end{array}$ & $\begin{array}{l}\text { QTL peak } \\
(\mathrm{CM})\end{array}$ & $\begin{array}{l}\text { QTL peak } \\
\text { (LOD) }\end{array}$ & $\begin{array}{l}\text { Closest } \\
\text { marker }\end{array}$ & $\operatorname{Var}(\%)$ & LOD & $\operatorname{Var}(\%)$ & K-value & $p$-value & $\begin{array}{l}\text { Marker } \\
\text { effect }\end{array}$ & $p$-value \\
\hline \multicolumn{12}{|c|}{ IV (GW = LOD4.3) } \\
\hline \multirow[t]{9}{*}{$\mathrm{OT}^{\mathrm{a}}$} & $102.3-151.5$ & 149.6 & 17.4 & SNPM04501 & 60.8 & 17.6 & 61.2 & 51.1 & 0.0001 & $2.16(+)$ & 0.0000000 \\
\hline & & & & SNPM00967 & & & & & & $2.16(+)$ & 0.0000000 \\
\hline & & & & SNPM00144 & & & & & & $2.16(+)$ & 0.0000000 \\
\hline & & & & SNPM01034 & & & & & & $2.16(-)$ & 0.0000000 \\
\hline & & & & SNPM00150 & & & & & & $2.16(-)$ & 0.0000000 \\
\hline & & & & PA5_oSSR & & & & & & $2.15(-)$ & 0.0000000 \\
\hline & & & & PA3_OSSR & & & & & & $2.18(-)$ & 0.0000000 \\
\hline & & & & SNPE00431 & & & & & & $2.17(+)$ & 0.0000000 \\
\hline & & & & sPSc00328 & & & & & & $2.15(+)$ & 0.0000000 \\
\hline \multicolumn{12}{|c|}{ C14:0 (GW = LOD3.7) } \\
\hline \multirow[t]{9}{*}{$\mathrm{OT} 1^{\mathrm{a}}$} & $140.7-151.5$ & 149.6 & 6.2 & SNPM04501 & 48.3 & 5.7 & 26.5 & 24.9 & 0.0001 & $0.04(-)$ & 0.0000000 \\
\hline & & & & SNPM00967 & & & & & & $0.04(-)$ & 0.0000000 \\
\hline & & & & SNPM00144 & & & & & & $0.04(-)$ & 0.0000000 \\
\hline & & & & SNPM01034 & & & & & & $0.04(+)$ & 0.0000000 \\
\hline & & & & SNPM00150 & & & & & & $0.04(+)$ & 0.0000000 \\
\hline & & & & PA5_OSSR ${ }^{a}$ & & & & & & $0.04(+)$ & 0.0000000 \\
\hline & & & & PA3_OSSR & & & & & & $0.04(+)$ & 0.0000000 \\
\hline & & & & SNPE00431 & & & & & & $0.04(-)$ & 0.0000000 \\
\hline & & & & sPSC00328 & & & & & & $0.04(-)$ & 0.0000000 \\
\hline \multirow[t]{3}{*}{ T2 } & $61.2-62.1$ & 61.2 & 4.1 & SNPM04068 & 20.1 & 4.3 & 22.9 & 15.1 & 0.0005 & $0.03(+)$ & 0.0000000 \\
\hline & & & & SNPM01906 & & & & & & $0.03(+)$ & 0.0000000 \\
\hline & & & & SNPM04410 & & & & & & $0.03(-)$ & 0.0000000 \\
\hline T9 & $17.2-32.6$ & 17.2 & 4.5 & SNPM00343 & 21.9 & 4.0 & 21.5 & 17.7 & 0.0001 & $0.03(-)$ & 0.0000000 \\
\hline \multicolumn{12}{|c|}{ C16:0 (GW = LOD4.9) } \\
\hline \multirow[t]{9}{*}{$\mathrm{OT} 1^{\mathrm{a}}$} & $102.3-151.5$ & 149.6 & 21.5 & SNPM04501 & 69.4 & 22.3 & 70.2 & 55.2 & 0.0001 & $2.41(-)$ & 0.0000000 \\
\hline & & & & SNPM00967 & & & & & & $2.41(-)$ & 0.0000000 \\
\hline & & & & SNPM00144 & & & & & & $2.42(-)$ & 0.0000000 \\
\hline & & & & SNPM01034 & & & & & & $2.41(+)$ & 0.0000000 \\
\hline & & & & SNPM00150 & & & & & & $2.41(+)$ & 0.0000000 \\
\hline & & & & PA5_OSSR & & & & & & $2.37(+)$ & 0.0000000 \\
\hline & & & & PA3_OSSR & & & & & & $2.35(+)$ & 0.0000000 \\
\hline & & & & SNPE00431 & & & & & & $2.42(-)$ & 0.0000000 \\
\hline & & & & sPSC00328 & & & & & & $2.40(-)$ & 0.0000000 \\
\hline \multicolumn{12}{|c|}{ C16:1 (GW = LOD4.3) } \\
\hline \multirow[t]{2}{*}{ T9 } & $2.9-32.6$ & 22.0 & 10.7 & SNPM00331 & 44.2 & 10.7 & 44.2 & 36.0 & 0.0001 & $0.08(-)$ & 0.0000000 \\
\hline & & & & SNPM00922 & & & & & & $0.08(+)$ & 0.0000000 \\
\hline \multicolumn{12}{|c|}{ C18:0 (GW = LOD3.8) } \\
\hline $\mathrm{OT}^{\mathrm{a}}$ & $140.7-151.5$ & 151.1 & 6.4 & sPSC00314 & 30.5 & 6.8 & 30.9 & 22.1 & 0.0001 & $0.14(-)$ & 0.0000001 \\
\hline OT4 & $158.4-176.5$ & 165.1 & 4.9 & SNPM00121 & 54.2 & 4.8 & 23.5 & 16.6 & 0.0001 & $0.02(+)$ & 0.0000020 \\
\hline
\end{tabular}


Table 2 QTLs linked to iodine value (IV) and fatty acid composition (FAC) in the OxG interspecific mapping population. QTLs identified using Interval Mapping (IM), the Multiple-QTL Model (MQM), the Kruskal-Wallis non-parametric tests (KW) and G Model (GM) (Continued)

\begin{tabular}{|c|c|c|c|c|c|c|c|c|c|c|c|}
\hline \multirow[t]{2}{*}{ T9 } & \multirow[t]{2}{*}{$13.4-24.8$} & \multirow[t]{2}{*}{22.0} & \multirow[t]{2}{*}{5.0} & SNPM00331 & \multirow[t]{2}{*}{23.8} & \multirow[t]{2}{*}{5.0} & \multirow[t]{2}{*}{23.8} & \multirow[t]{2}{*}{19.0} & \multirow[t]{2}{*}{0.0001} & $0.03(+)$ & 0.0000003 \\
\hline & & & & SNPM00922 & & & & & & $0.03(-)$ & 0.0000005 \\
\hline \multicolumn{12}{|l|}{ C18:1 (GW = LOD4.0) } \\
\hline \multirow[t]{9}{*}{$\mathrm{OT}^{\mathrm{a}}$} & \multirow[t]{9}{*}{$112.6-151.5$} & \multirow[t]{9}{*}{149.6} & \multirow[t]{9}{*}{16.3} & SNPM04501 & \multirow[t]{9}{*}{59.5} & \multirow[t]{9}{*}{16.9} & \multirow[t]{9}{*}{60.1} & \multirow[t]{9}{*}{49.5} & \multirow[t]{9}{*}{0.0001} & $2.29(+)$ & 0.0000000 \\
\hline & & & & SNPM00967 & & & & & & $2.17(+)$ & 0.0000000 \\
\hline & & & & SNPM00144 & & & & & & $2.18(+)$ & 0.0000000 \\
\hline & & & & SNPM01034 & & & & & & $2.17(-)$ & 0.0000000 \\
\hline & & & & SNPM00150 & & & & & & $2.29(-)$ & 0.0000000 \\
\hline & & & & PA5_OSSR ${ }^{a}$ & & & & & & $2.39(-)$ & 0.0000000 \\
\hline & & & & PA3_OSSR ${ }^{a}$ & & & & & & $2.06(-)$ & 0.0000000 \\
\hline & & & & SNPE00431 & & & & & & $2.07(+)$ & 0.0000000 \\
\hline & & & & sPSc00328 & & & & & & $2.30(+)$ & 0.0000000 \\
\hline \multicolumn{12}{|l|}{ C18:2 (GW = LOD3.8) } \\
\hline $\mathrm{T} 3(\mathrm{CW}=\mathrm{LOD} 1.7)$ & 46.9-65.2 & 63.3 & 2.1 & SNPM00462 & 10.9 & 2.3 & 11.5 & 8.9 & 0.0050 & $0.17(+)$ & 0.0017218 \\
\hline OT6 (CW = LOD2.7) & $38.9-54.5$ & 45.8 & 3.1 & SNPM05061 & 35.2 & 3.3 & 40.2 & 11.0 & 0.0010 & $0.16(-)$ & 0.0000052 \\
\hline
\end{tabular}

${ }^{\mathrm{a} A f t e r}$ fine mapping

GW: $95 \%$ Genome-wide significant LOD threshold

CW: $95 \%$ Chromosome-wide significant LOD threshold

size of the OxG population and the short distance ( $975 \mathrm{kbp})$ on the physical map. Using GM, the nine markers were detected to have a significant effect close to $2.20(p=0.0)$ (Table 2). This result indicated that the maternal UP1026 genotype ( $a a)$ had an increasing effect on IV compared to the T128 genotype $(a b)$ for SNPM04501, SNPM00967, sPSc00328, SNPM00144 or SNPE00431. In contrast, $a a$ showed reduced levels of IV compared with $a b$ when genotyped with SNPM01034, SNPM00150, PA5_oSSR or PA3_oSSR (Fig. 5, a). The difference in mean IV between the two genotypes improved to $4.47(73.5 \pm 1.9$ vs. $69.0 \pm 1.9)$ compared to 3.67 estimated previously using the RFLP marker, pOP-CB00075a by Singh et al. [8].

The same group of markers were also closely linked to the QTL for C18:1, with similar allelic effects as observed on IV (Fig. 5, b). These markers detected a greater difference $(4.8 \%)$ in $\mathrm{C} 18: 1$ content compared to the $2.7 \%$ explained by pOP-CB00075a previously. Another QTL revealed by the same group of markers was for C16:0 content. The estimated marker effect of $2.4 \%$ $(p=0.0)$ had increasing alleles from the other parent, compared to that for IV and C18:1 which agrees with the strong negative correlation between the levels of saturated (C16:0) and unsaturated FAs (IV and C18:1). The difference in the C16:0 mean values of the homozygous and heterozygous genotypes also increased to $5.1 \%$ from the $3.8 \%$ previously reported (pOP-CB00075a). In addition to the three major QTLs, these markers also had a minor effect of $0.04 \%(p=0.0)$ on C14:0 with the increasing alleles inherited in the same direction as C16:0. The difference in C14:0 content between genotypes $a a(0.24 \% \pm 0.07)$ and $a b(0.33 \% \pm 0.09)$ was also relatively low at $0.1 \%$. With respect to $\mathrm{C} 18: 0$, the refined

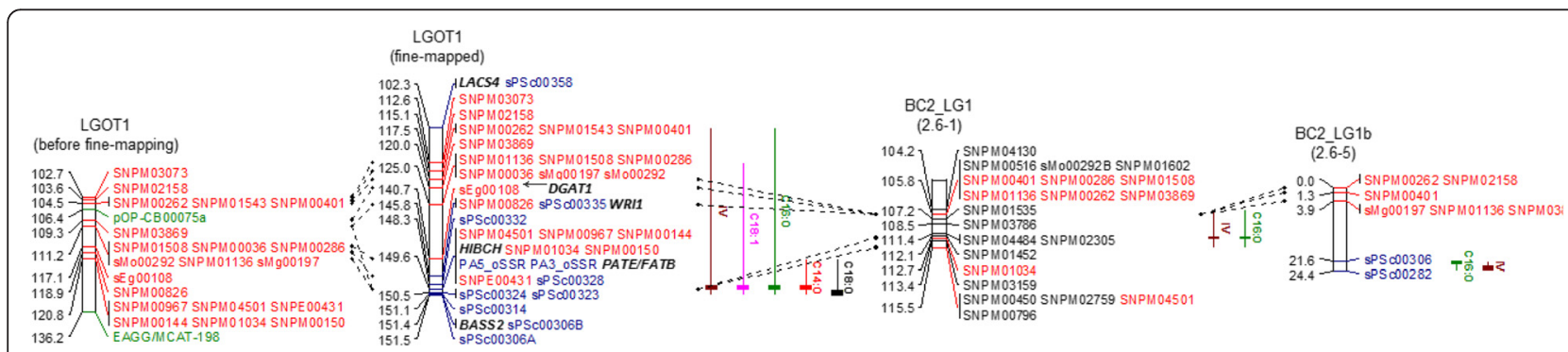

Fig. 4 Fine-mapping of QTL intervals with candidate markers and cross-validation of QTLs in two independent $B C_{2}$ crosses. Similar QTLs between LGOT1 (OXG mapping population) and LGs 1 and $1 \mathrm{~b}$ of $\mathrm{BC}_{2}$ validation crosses (2.6-1 and 2.6-5) are indicated by common markers (in red) and candidate SSR markers (in blue) 


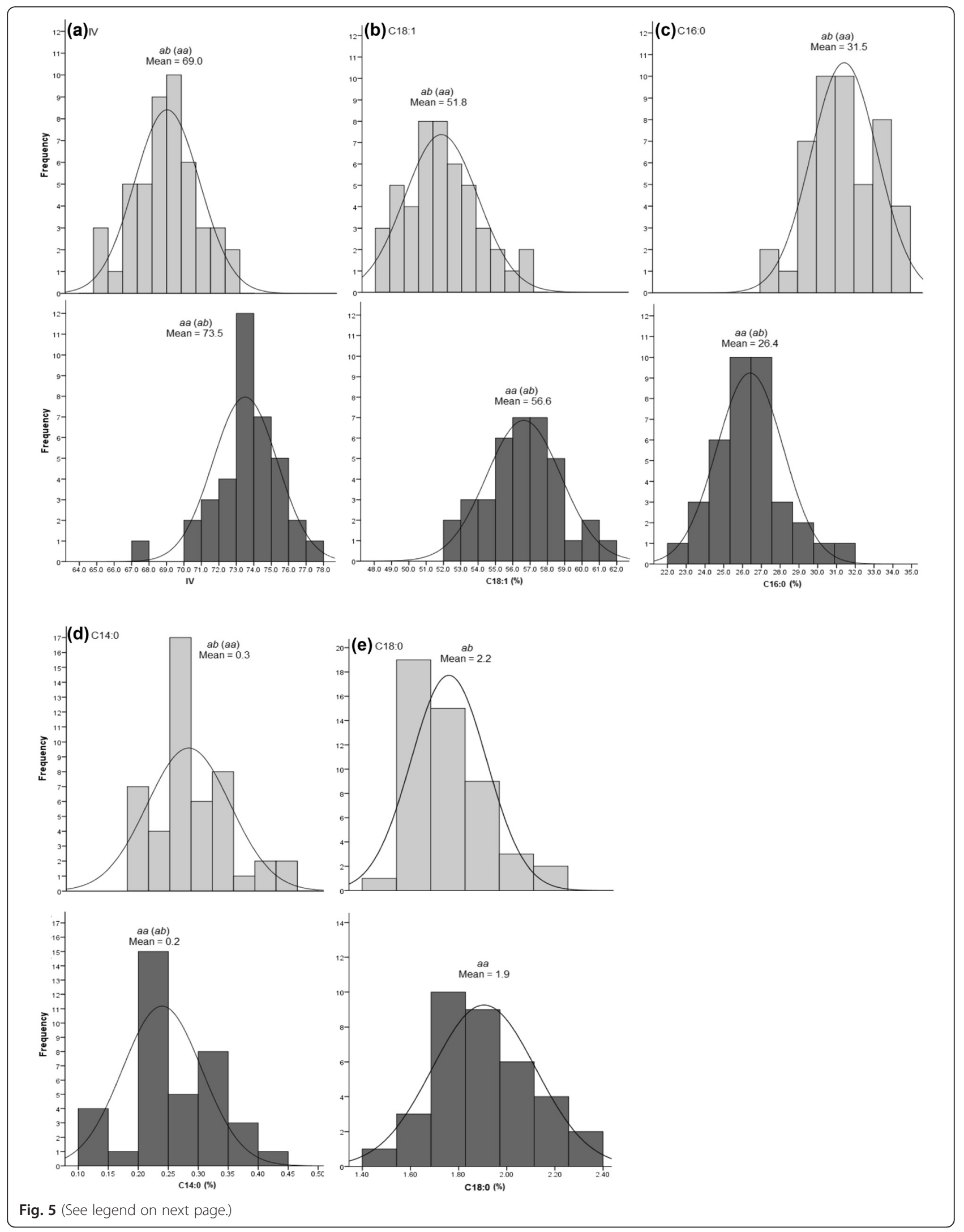


(See figure on previous page.)

Fig. 5 Distribution of IV and FAC phenotypes in OxG hybrids genotyped by the closest markers linked to the QTLs on LGOT1. The upper panel (light grey) is of hybrids with genotype $a b$ ( $a a)$ while the lower panel (dark grey) shows the phenotypic distribution of genotype $a a(a b)$ in SNPM04501, SNPM00967, sPSC00328, SNPM00144 or SNPE00431 (SNPM01034, SNPM00150, PA5_OSSR or PA3_oSSR) for IV (a), C18:1 (b), C16:0 (c) and C14:0 (d). For C18:0 (e), the $a b$ and aa genotypes are observed in SPSC00314

QTL interval (140.7-151.5 cM) revealed a new candidate SSR marker sPSc00314 at the QTL peak with a negative effect of $0.14 \%(p=0.0000001)$. A difference of $0.3 \%$ in C18:0 was observed between the $a a$ and $a b$ genotypes of sPSc00314 (Fig. 5, e). On the genome scaffold (p5_sc00104), sPSc00314 was located between PATE/ $F A T B$ and BASS2 with an estimated distance of $\sim 247$ $\mathrm{kbp}$ and $68 \mathrm{kbp}$, respectively. Therefore, it is still unclear at this point which of the genes, if any, is influencing the minor QTL for C18:0.

\section{Validation of QTLs for IV and C16:0 in $\mathrm{BC}_{2}$}

In this study, the QTLs detected for IV and C16:0 in the OxG mapping population were tested for validation in the two $\mathrm{BC}_{2}$ crosses-2.6-1 and 2.6-5. In 2.6-1, a major QTL was detected for IV with LOD8.7 on LG1. The $11.3 \mathrm{cM}$ confidence interval (104.2-115.5 cM) containing one SSR and 20 SNPs was then aligned to LGOT1 (in OxG) using nine transferable markers (SNPM00286, SNPM00401, SNPM01508, SNPM01136, SNPM00262, SNPM03869, SNPM01034, SNPM03159 and SNPM04501) which clearly showed that the same region was affecting IV in both crosses (Fig. 4). Of these markers, SNPM01034 underlying the QTL peak revealed three genotypes $a a, a b$ and $b b$ - in the 2.6-1 palms. The $a a$ genotype, similar to that observed in OxG, differentiated the IV mean $(67.3 \pm 2.0)$ from the $b b$ genotype $(64.1 \pm 1.9)$ with $p=0.011$ but, no significant difference observed in genotypes $a a$ vs. $a b(p=0.228)$ and $b b$ vs. $a b(p=0.087)$. The same marker SNPM01034 (LOD4.3) was also detected flanking a putative QTL peak for C16:0 with minor effect.

The QTLs with overlapping confidence intervals for IV and C16:0 were also identified in the 2.6-5 cross on a subgroup of LG1 (labelled as LG1b). When compared with LGOT1 in OxG, the same QTL region encompassing the common marker sPSc00306 was also located at the end of the LG1b. For IV, the QTL peak showed a high LOD score (5.6) with the confidence interval (21.6-24.4 cM) and contained two candidate SSR markers, sPSc00306 and sPSc00282, with estimated effects of 1.5-1.7 IV units. For the closest marker sPSC00306, the maternal genotype $(a a)$ showed significantly $(p=0.05)$ lower unsaturation (IV) $62.4( \pm 2.3)$ compared to $65.6( \pm 3.5)$ in the paternal genotype $(a b)$. The sPSc00306 also showed a significant effect of $0.9 \%(p=0.0021634)$ and the $a a$ and $a b$ genotypes revealed a significant $(p=0.05)$ mean difference $(36.0 \% \pm 2.1 v s$. $33.6 \% \pm 3.2)$ in $\mathrm{C} 16: 0$ content.

\section{Additional QTLs detected in the $\mathrm{BC}_{2}$}

The 2.6-1 and 2.6-5 crosses revealed additional QTLs for C18:2 on LG4 which were not detected in OxG. For 2.6-5, the QTL in the confidence interval 3.9-9.4 cM enclosed seven markers (SNPM00203, SNPM00151, SNPM00249, SNPM00348, SNPM02910, SNPM01114 and SNPM04449). Of these, the closest flanking markers to the QTL peak (at $9.4 \mathrm{cM}$ ) were SNPM04449 and SNPM01114 with estimated effects of $0.9 \%(p=0.0008687)$ and $0.5 \%(p=0.0018213)$, respectively. In the 2.6-1 cross, similar QTL (indicated by common markers) although significant at the chromosome-wide level rather than the genome-wide level were also detected on LG4 with LODs ranging from 3.4-3.8. The left-right flanking markers were SNPM00971, SNPM04449, SNPM00203, SNPM00348 and SNPM00249 at 3.4 cM and SNPM00563, SNPM00692 and SNPM00151 at $5.5 \mathrm{cM}$ (Additional file 5).

In comparison, more new QTLs were detected in 2.6-1 than in 2.6-5. These include i. C18:1 (22.7-24.6 cM on LG4), ii. C18:1 (35.6-38.7 cM on LG8), iii. IV (63.1$68 \mathrm{cM}$ on LG15), iv. C16:1 (59.5-66.6 cM on LG15) and, v. C18:2 (53.2-60.3 cM on LG15). All were minor QTLs, significant at the $95 \%$ chromosome-wide level.

\section{Discussion}

This study extended the mapping of QTLs linked to IV and $\mathrm{FAC}$ in the OxG interspecific mapping population initiated by Singh et al. [8]. The preliminary map constructed with 252 markers localized 12 QTLs mostly loosely flanked by AFLP and RFLP markers. Therefore, in this study, a $4.7 \mathrm{x}$ more saturated genetic map was used to localize the QTLs and improve coverage. A total of 10 genome-wide and two putative QTLs for IV and various FAs were identified on six improved LGs (OT1, T2, T3, OT4, OT6 and T9), which included 11 of the QTLs detected previously. The results indicated that the current SSR and SNP-based genetic map was effective in revealing QTLs with the only exception being the minor QTL for C14:0 reported earlier on group 8 (the present LGT2). However, a new putative QTL was revealed for C14:0 at the nearby region of the same LG. The shift in location could indicate a more precise estimation of the QTL with the improved map resolution on LGT2, with a similar situation having been reported in eggplant [34].

The detected QTLs at this stage can only be considered to be specific to the OxG cross which would limit application of the markers for MAS. Mapping families 
created via a sequential series of backcrosses and selfpollination would ideally help validate the QTLs as reported in rapeseed [35], maize [36, 37] and soybean [38]. However such mapping families are not readily available for a perennial crop like oil palm and it would take about 10 years to create each generation, with initial phenotyping [39, 40], apart from the huge investment required in land, labour and management. It is for this reason that, to date, QTLs for IV and FAC in oil palm have only been reported in single crosses involving a $\mathrm{BC}_{1}$, tenera $\mathrm{x}$ dura $\mathrm{F}_{1}[16,17]$ and an OxG hybrid [8]. In this study, we used two independent $\mathrm{BC}_{2}$ pseudo-crosses (2.6-1 and 2.6-5) created by introgression of E. oleifera into T128 germplasm materials to try to validate the QTLs detected in the OxG hybrid population. To our knowledge, this is the first attempt to validate QTLs for FAC in oil palm of similar genetic backgrounds.

The two $\mathrm{BC}_{2}$ crosses are related by pedigree and also genetically linked with the T128 germplasm (Fig. 1). Here we adopted a strategy to evaluate the QTLs through an independent analysis with subsequent comparison of their locations. However, our results showed that only the major QTLs for IV and C16:0 were successfully cross-validated through a common location, and all similarly revealed a large proportion of phenotypic variance (43.0-53.0 \% for IV and 31.0-62.0 \% for C16:0) in both $2.6-1$ and 2.6-5. The common QTLs in $\mathrm{BC}_{2}$ revealed that the different genotypes of closely linked markers also showed distinct levels for IV and C16:0 content. The finding is of interest as IV represents the cumulative unsaturation in palm oil and it has always been used as an indicator in selecting for higher unsaturation overall in breeding programs [41], whereas the QTL for C16:0 can complement the prediction by indicating the palmitic (saturation) level. It is however noted that the QTL for C18:1 could not be crossvalidated in the two $\mathrm{BC}_{2}$ populations even though $\mathrm{C} 18: 1$ is a major component contributing to IV and in this study was highly correlated with IV and negatively correlated with C16:0. The small size of the mapping families could have limited the detection power for the QTL analysis, resulting in the lack of detection of the QTLs in the $\mathrm{BC}_{2}$ crosses. A similar observation was made in maize about the effect of population size when a sub sample (about $1 / 3$ of the larger population) only revealed about $1 / 5$ of the QTLs observed in larger samples [42].

In addition to validating QTLs in the interspecific $\mathrm{BC}_{2}$, eight of the identified QTLs were similar to those reported previously using either a $\mathrm{BC}_{1}$ or a tenera $\times$ dura cross [16, 17]. Multiple QTLs for C14:0, C16:0, $\mathrm{C} 18: 0$ and C18:1 were reported previously in the respective intervals $0-25.6,0-7.0,0-5.8$ and $0-6.0 \mathrm{cM}$ on LG9 in the tenera $\mathrm{x}$ dura mapping family. The intervals were aligned with the current QTLs on LGT9 using three common markers, mEgCIR3787, mEgCIR3592 and mEgCIR3305, pointing to a similar map region. In the previous studies by Montoya et al. [16, 17], the intervals in LG4 (199.8-234.4 cM and 201.8-216.0 cM) were reported to be linked to $\mathrm{C} 18: 0$ and $\mathrm{C} 18: 1$, respectively. Similar regions affecting the QTLs were also detected in the present OxG (C18:0) and 2.6-1 (C18:1) crosses, determined using the common markers mEgCIR3535, mEgCIR1753 and mEgCIR3310 mapped in both the studies. Another possible common QTL (determined using markers mEgCIR3649, mEgCIR3282 and mEgCIR0800) was C14:0 on LGT2 which was also previously reported on the same $\mathrm{LG}$ in the $\mathrm{BC}_{1}$ [16]. The putative QTL linked to C18:2 on LGT3 and LGOT6 were similar to that reported previously. The QTL on LGT3 matched the genomic region reported previously for a $\mathrm{BC}_{1}$ population [17], as revealed by the common marker mEgCIR0425, mapping in the same region. With respect to LGOT6, the QTL region was very close to that reported previously for the same trait by Singh et al. [8]. The above comparison has provided useful information for comparing QTLs linked to FAC by different research groups. We compiled and compared a total 60 QTLs linked to IV and FAC (14 in OxG, 12 in two $\mathrm{BC}_{2}, 15$ in tenera $\mathrm{x}$ dura and 19 in $\mathrm{BC}_{1}$ ) across the different mapping families. However, very low percentages of the QTLs were common across two $(20.0 \%)$ to three $(2.0 \%)$ of the crosses and none at all in more than three crosses. This highlights that in QTL analysis, even for a highly heritable trait such as FAC, favourable alleles are likely to be population-specific requiring careful selection for implementation in MAS. Nevertheless, this study revealed a core set of markers (SNPM04501, SNPM00967, sPSc00328, SNPM00144, SNPE00431, SNPM01034, SNPM00150, PA5_oSSR and PA3_oSSR) that can be useful for MAS, especially in genetic backgrounds involving the T128 and E. oleifera parental palms. As the palm materials are commonly available and accessible to the oil palm industry, the markers will have practical application for selecting favourable alleles for unsaturation ( $v s$. saturation) in interspecific hybrids and their backcrosses.

Detection of similar QTLs for IV and C16:0 in both OxG and $\mathrm{BC}_{2}$ allowed the underlying QTL interval to be compared to the recently published oil palm genome build [18]. This study is also the first to describe attempts at fine-mapping of targeted QTL regions for IV and various FAC, by exploiting the whole genome sequence data of oil palm. The genomic region of about $6 \mathrm{kbp}$ showed the presence of an interesting gene with high similarity to PATE/FATB in oil palm [GenBank: XM_010916712.1, XM_010916714.1, DQ422858, AF424808, AF430248, AF147879 and AF541880] and coconut [GenBank: JF338904 and JF338903]. Comparison of genetic maps using the common markers 
mEgCIR0008, mEgCIR3428 and mEgCIR3819 estimated that the current map position of PATE/FATB in LGOT1 is in accordance with Montoya et al. [16]. However, the authors did not associate the gene or region around the gene with any QTL for IV or FAC.

In oil palm, PATE/FATB encodes the palmitoyl-ACP thioesterase that actively releases $\mathrm{C} 16: 0$ from $\mathrm{C} 16: 0-\mathrm{ACP}$ and allows the resulting non-esterified FA to be incorporated into TAG $[15,43]$ and is one of the main factors responsible for the relatively high saturation levels in palm oil [44]. A similar role was reported for PATE/ FATB in oil biosynthesis in cotton seed [45]. Apart from a strong substrate preference for C16:0, the substrate specificity of palmitoyl-ACP thioesterase also extends to other saturated acyl-ACPs, including C14:0- and C18:0ACPs $[46,47]$. This was shown in other species by overexpression of PATE/FATB in Arabidopsis thaliana $[48,49]$ and canola seeds [50] which also had an elevated concentration of C14:0. This is in agreement with the strong positive correlation observed in this study between the C16:0 and C14:0 phenotypes. In contrast, the phenotypic data for levels of C16:0 had a strong negative correlation with C18:1 levels which indicates that a reduction of $\mathrm{C} 16: 0$ is associated with increased C18:1. This was also observed in maize seeds where a mutated FATB allele caused a dramatic reduction of $\mathrm{C} 16: 0$ in the oil and increased the level of unsaturated FAs [47]. The truncated FATB was reported responsible for the non-functioning of a critical catalytic domain and this could have resulted in the channelling of more $\mathrm{C} 16: 0-\mathrm{ACP}$ for elongation and subsequent desaturation into unsaturated acyl chains, such as C18:1-ACP. It was also suggested that at least one of the palmitoyl-ACP thioesterase isoforms in oil palm can hydrolyze C18:1 efficiently [51]. This could also explain the co-localization of QTLs for IV, C14:0, C16:0, C18:0 and C18:1 on LGOT1 found in this study. Therefore, the next step is to evaluate the identified PATE/FATB gene in palms with varying contents of $\mathrm{C} 16: 0$ and $\mathrm{C} 18: 1$.

Another interesting region was at $\sim 294 \mathrm{kbp}$ (including non-sequenced gaps) from PATE/FATB $(661,598$ - 666,373 bp in p5_sc00104). This genomic region $(\sim 21 \mathrm{kbp})$ contained a gene with significant similarity to $H I B C H$ in both oil palm [GenBank: XR_831088.1， XM_010916727.1， XM_010916728.1, XM_010916729.1 and XM_010916731.1] and date palm [GenBank: XM_008795208.1]. In oil palm, information about the role of $H I B C H$ (found in mitochondrial) associated with FA and TAG biosynthesis is very limited. This enzyme is reportedly involved in the degradation of FAs (beta oxidation) in Camelina sativa [52] which takes place in mitochondrial and the peroxisomes. In coconut, $\mathrm{HIBCH}$ was reported as being down-regulated during the production and accumulation of oil [53].

Several other interesting genes and TF encoding key enzymes involved in both the FA and TAG pathways, including BASS2, LACS4, DGAT1 and WRI1, were also found in proximity to the QTL peak. BASS2 [GenBank: XM_010916675.1 and XM_010916676.1] is reported to play a major role in channelling pyruvate into plastids [54] for conversion into acetyl-CoA and malonyl-CoA the main substrates to initiate synthesis of FA. At the final stage of FA biosynthesis, non-esterified FAs are converted into acyl-CoA by long chain acyl-CoA synthetase and later transferred through the plastid envelope into the ER for synthesis of TAGs $[13,55,56]$. On the current LGOT1, the long chain acyl-CoA synthetase family member 4 (LACS4) [GenBank: XM_010917352.1, XM_010927422.1, XR_832599.1 and XM_008790523.1] was identified at $112.9 \mathrm{cM}$ close to the end of the QTL interval. In A. thaliana, LACS4 showed greatest preference for the C16:0 substrate when expressed in E. coli. Substrate preference for various FAs was reported in the following order: C16:0 > C16:1 > C18:2 > C18:1 > C20:1 > C18:0 [56]. This may again explain the co-localization of QTLs for C16:0 with other FAs on LGOT1 where genes, such as PATE/FATB and LACS4, show pleiotropic effects contributing to the complex interactions with the substrates in FA synthesis.

In this study, DGAT is the only gene detected in the QTL region that is involved in formation of TAGs in the acyl-CoA-dependent (Kennedy) pathway [13, 57]. The $\sim 28$ kbp genomic region (between SNPM01136, sMg00197, SNPM01508, SNPM00286, sMo00292, SNPM00036 and sEg00108) has high sequence similarities to DGAT1 in oil [GenBank: XM_010927169.1, XM_010927170.1, XM_010927171.1 and XM_010927172.1] and date palms [GenBank: XM_008794980.1 and XM_008794981.1]. In oil palm, DGAT1 is known to interact with other acyltransferases, in particular, $D G A T 2$, to synthesize TAG $[14,50]$. It is generally agreed that DGAT1 plays an important role in one of the oil palm lipid production pathways. However, information on the specificity and selectivity of each paralogue of DGAT in oil palm is still lacking and requires further study to establish their function and effect on the composition of FA in palm oil.

In addition to the key enzymes mentioned above, we identified a WRI1 TF co-localized with two markers (sPSc00335 and SNPM00826) at $145.8 \mathrm{cM}$ in the QTL region on LGOT1. The oil palm WRI1 [GenBank: XM_010916833.1] has high similarity to that in date palm [GenBank: XM_008777490.1 and XM_008811881.1], plum [GenBank: XM_008223524.1], Euphrates poplar [GenBank: XM_011006767.1] and grape [GenBank: XM_010662724.1]. This TF has long been considered 
a master regulator directly influencing a number of enzymes in the FA and TAG synthesis pathways in plants [13, 57-61], including oil palm [14, 15].

\section{Conclusions}

This study for the first time extensively compared the QTLs linked to IV and FAC across various interspecific genetic backgrounds. The detected QTLs, to some extent, are population specific although the major QTLs can be observed across related genetic backgrounds. A core set of markers with practical application in selection for higher unsaturation in FA levels were described. The candidate markers linked to the QTLs revealed significant allelic and genotypic differences associated with IV and FAC, suggesting that the markers are potentially useful in MAS, at least in the genetic backgrounds described. The fine-mapping approach employed in this study also proved effective in identifying candidate genes and a transcription factor affecting IV and FAC in palm oil. The identified genes and transcription factor, $H I B C H$, PATE/FATB, BASS2, LACS4, DGAT1 and WRI1 underlying the overlapping QTL confidence intervals for IV, C14:0, C16:0, C18:0 and C18:1, have provided valuable information on several potential candidate genes and a transcription factor which are known in other species to strongly influencing the biosynthesis of FA and TAG. Thus, to fully understand the interaction and effects of these genes, the listed candidate genes will be further studied to determine their expression levels in palms with different IV and FAC.

\section{Availability of supporting data}

The sequence information for the SNP and SSR markers is available at http://genomsawit.mpob.gov.my

\section{Additional files}

Additional file 1: Mapping candidate markers for various fatty acid related genes in the OXG linkage map. Candidate SNP markers (SNPE, in pink) for palmitoyl-ACP thioesterase (PATE/FATB), oleoyl-CoA desaturase (FAD2), linoleoyl-CoA desaturase (FAD3), enoyl-ACP reductase (ENR1) and stearoyl-ACP desaturase (SAD) mapped onto LGs OT1, T2, OT11, OT12 and T14. Candidate SSR markers (_OSSR and SPSC, in blue) also developed for ketoacyl-ACP synthase I (KASI), acetoacetyl-CoA thiolase (AACT), long chain acyl-CoA synthetase (LACS4), AP2-like ethylene-responsive TF (WR/1), 3-hydroxyisobutyryl-CoA hydrolase-like protein $3(H I B C H)$, sodium/ metabolite cotransporter (BASS2), PATE/FATB and SAD. (PDF $56 \mathrm{~kb}$ )

Additional file 2: Pearson's correlation coefficients for iodine value (IV) and fatty acid composition (FAC) in palm oil of OxG mapping population. (PDF $13 \mathrm{~kb}$ )

Additional file 3: Pearson's correlation coefficients for iodine value (IV) and fatty acid composition (FAC) in palm oil of $\mathrm{BC}_{2}(2.6-1)$ validation cross. (PDF $13 \mathrm{~kb}$ )

Additional file 4: Pearson's correlation coefficients for iodine value (IV) and fatty acid composition (FAC) in palm oil of $\mathrm{BC}_{2}(2.6-5)$ validation cross. (PDF $13 \mathrm{~kb}$ )
Additional file 5: Co-linearity of markers between the $\mathrm{OxG}$ and $\mathrm{BC}_{2}$ (2.6-1 \& 2.6-5) populations as observed in six linkage groups hosting QTLs (OT1, T2, T3, OT4, OT6 and T9). (PDF 96 kb)

\section{Abbreviations}

BLASTN: similarity search of the NCBI nucleotide database using a nucleotide query; BLASTX: similarity search of the NCBI protein database using a translated nucleotide query; cM: centimorgan map distance; LOD: logarithm of odds; nt: NCBI nucleotide collection; nr: NCBI non-redundant protein sequences database; P5: E. guineensis (AVROS, pisifera) $5^{\text {th }}$ genome build; p5_scxxxxx: E. guineensis (AVROS, pisifera) $5^{\text {th }}$ genome scaffolds; PAx_oSSR: Candidate SSR marker for palmitoyl-ACP thioesterase; PCR: polymerase chain reaction; refseq_protein: NCBI reference proteins database; SD: standard deviation; SNPMxxxxx: single nucleotide polymorphism marker; SNPExxxxx: candidate single nucleotide polymorphism marker; sPSCXxxxx: candidate simple sequence repeat marker.

\section{Competing interest}

The authors declare that they have no competing interests.

\section{Authors' contributions}

$\mathrm{RS}, \mathrm{RS}, \mathrm{SM}, \mathrm{FM}, \mathrm{N}-\mathrm{CT}, \mathrm{ZY}$ and $\mathrm{KK}$ conceived and designed the experiments. $\mathrm{N}-\mathrm{CT}, \mathrm{ZY}$ and KK carried out molecular experiments and data analyses. LLET, $\mathrm{N}-\mathrm{CT}$ and RS participated in the SNP experimental design and coordination. JJ assisted with the statistical analysis of the phenotypic and marker data. LLET, NA, RR and K-LC provided bioinformatics support and involved in mapping the QTLS to genome build. JJ, SM, FM, RS, RN, MDA, MI, AK, XA, KS and LCC advised on the design of the study and contributed materials as well as reagents. N-CT, ZY and KK drafted the manuscript. RS, SM, RS and FM assisted with interpretation of data and revised the manuscript critically. All authors read and approved the final manuscript.

\section{Acknowledgements}

The authors would like to thank the Director-General of MPOB for permission to publish this paper. Part of the work was carried out at Biometris, Wageningen University and Research Centre, the Netherlands. The authors thank Dr. Rex Bernardo from University of Minnesota for permission to use the G Model software. We would like to thank Mr. Andy Chang Kwong Choong for his valuable comments on this manuscript. We would also like to extend our appreciation to Ms. Maizura Azwanie Mohd Zarawi for her technical assistance in PCR. The project was funded by the Malaysian Palm Oil Board (MPOB).

\section{Author details}

${ }^{1}$ Malaysian Palm Oil Board (MPOB), P.O. Box 10620, 50720 Kuala Lumpur, Malaysia. ${ }^{2}$ Plant and Crop Sciences, Sutton Bonington Campus, University of Nottingham, Sutton Bonington, Loughborough LE12 5RD, UK. ${ }^{3}$ School of Biosciences, University of Nottingham Malaysia Campus, Jalan Broga, 43500 Semenyih, Selangor, Malaysia. ${ }^{4}$ Biometris, Wageningen University and Research Centre, P.O. Box 100, 6700 AC Wageningen, The Netherlands. ${ }^{5}$ United Plantations Bhd., Jendarata Estate, 36009 Teluk Intan, Perak, Malaysia.

Received: 22 August 2015 Accepted: 28 March 2016

Published online: 14 April 2016

\section{References}

1. Teoh $\mathrm{CH}$. The palm oil industry in Malaysia: from seed to frying pan. WWF Malaysia. 2002. http://assets.panda.org/downloads/oilpalmchainpartaandb_ esri.pdf. Accessed 25 May 2015

2. Choo YM, Kalanithi N. Research advancements in palm oil nutrition. Eur J Lipid Sci Technol. 2014;116:1301-15.

3. Sambanthamurthi R, Sundram K, Tan Y-A. Chemistry and biochemistry of palm oil. Progr Lipid Res. 2000;39(6):507-58.

4. FAQs-MPOB: What is the fatty acid composition of palm oil and its associated products? http://www.mpob.gov.my/en/faqs. Accessed 25 May 2015.

5. Mohd Din A, Rajanaidu N, Jalani BS. Performance of Elaeis oleifera from Panama, Costa Rica, Colombia and Honduras in Malaysia. J Oil Palm Res. 2000;12:71-80. 
6. Murphy DJ. Oil palm: future prospects for yield and quality improvements. Lipid Technol. 2009;21(11\&12):257-60.

7. Murphy DJ. The future of oil palm as a major global crop: opportunities and challenges. J Oil Palm Res. 2014;26(1):1-24

8. Singh R, Tan SG, Panandam JM, Rahman RA, Ooi LC-L, Low E-TL, et al. Mapping quantitative trait loci (QTLs) for fatty acid composition in an interspecific cross of oil palm. BMC Plant Biol. 2009;9:114.

9. Kushairi A, Rajanaidu N, Jalani BS. PORIM Series 2. PORIM TT No. 16. PORIM Information Series. Bangi: Malaysian Palm Oil Board; 1999.

10. Rajanaidu N, Ainul MM. Conservation of oil palm and coconut genetic resources. In: Normah MN, Chin HF, Reed BM, editors. Conservation of tropical plant species. New York: Springer Science Business Media; 2013. p. $189-212$.

11. Ting N-C, Jansen J, Mayes S, Massawe F, Sambanthamurthi R, Ooi LC-L, et al. High density SNP and SSR-based genetic maps of two independent oil palm hybrids. BMC Genomics. 2014;15:309.

12. Ohlrogge JB, Jaworski JG. Regulation of fatty acid synthesis. Annu Rev Plant Physiol Plant Mol Biol. 1997;48:109-36.

13. Chapman KD, Ohlrogge JB. Compartmentation of triacylglycerol accumulation in plants. J Biol Chem. 2012;287(4):2288-94.

14. Tranbarger TJ, Dussert S, Joät J, Argout X, Summo M, Champion A, et al. Regulatory mechanisms underlying oil palm fruit mesocarp maturation, ripening, and functional specialization in lipid and carotenoid metabolism. Plant Physiol. 2011;156(2):564-84.

15. Bourgis F, Kilaru A, Cao X, Ngando-Ebongue G-F, Drira N, Ohlrogge JB, et al. Comparative transcriptome and metabolite analysis of oil palm and date palm mesocarp that differ dramatically in carbon partitioning. Proc Natl Acad Sci. 2011;108(44):12527-32.

16. Montoya C, Lopes R, Flori A, Cros D, Cuellar T, Summo M, et al. Quantitative trait loci (QTLs) analysis of palm oil fatty acid composition in an interspecific pseudo-backcross from Elaeis oleifera (H.B.K.) Cortés and oil palm (Elaeis quineensis Jacq.). Tree Genet Genomes. 2013;9:1207-25.

17. Montoya C, Cochard B, Flori A, Cros D, Lopes R, Cuellar T, et al. Genetic architecture of palm oil fatty acid composition in cultivated oil palm (Elaeis guineensis Jacq.) compared to its wild relative E. oleifera (H.B.K) Cortés. PLoS ONE. 2014; doi:10.1371/journal.pone.0095412.

18. Singh R, Ong-Abdullah M, Low ETL, Abdul Manaf MA, Rosli R, Rajanaidu N, et al. Oil palm genome sequence reveals divergence of infertile species in old and new worlds. Nature. 2013;500:335-9.

19. Ying J-Z, Shan J-X, Gao J-P, Zhu M-Z, Shi M, Lin H-X. Identification of quantitative trait loci for lipid metabolism in rice seeds. Mol Plant. 2012;5(4):865-75.

20. Lee M, Xia JH, Zou Z, Ye J, Rahmadsyah, Alfiko Y, et al. A consensus linkage map of oil palm and a major QTL for stem height. Sci Rep. 2015;5:8232.

21. Wang X, Jiang G-L, Green M, Scott RA, Hyten DL, Cregan PB. Quantitative trait locus analysis of saturated fatty acids in a population of recombinant inbred lines of soybean. Mol Breeding. 2012;30:1163-79.

22. PORIM. PORIM Test Method. In: Methods of test for palm oil and palm oil products. Bandar Baru Bangi: Palm Oil Research Institute Malaysia (PORIM); 1995.

23. Gabriel S, Ziaugra L, Tabbaa D. SNP genotyping using the Sequenom MassARRAY iPLEX platform. Curr Protoc Hum Genet. 2009; Chapter 2:Unit 2-12.

24. Van Ooijen JW. JoinMap ${ }^{\oplus}$ 4.1, software for calculation of genetic linkage maps in experimental populations; 2006. Kyazma B.V., Wageningen, the Netherlands.

25. Voorrips RE. MapChart: software for the graphical presentation of linkage maps and QTLs. J Hered. 2002;93(1):77-8.

26. Van Ooijen JW. MapQTL ${ }^{\bullet}$ 6, software for the mapping of quantitative trait loci in experimental populations of diploid species; 2009. Kyazma B.V., Wageningen, the Netherlands.

27. Bernardo R. Genomewide markers as cofactors for precision mapping of quantitative trait loci. Theor Appl Genet. 2013;126:999-1009.

28. Altschul SF, Madden TL, Schäffer AA, Zhang J, Zhang Z, Miller W, et al. Gapped BLAST and PSI-BLAST: a new generation of protein database search programs. Nucleic Acids Res. 1997;25(17):3389-402.

29. Thiel T, Michalek W, Varshney RK, Graner A. Exploiting EST databases for the development and characterization of gene-derived SSR-markers in barley (Hordeum vulgare L.). Theor Appl Genet. 2003;106:411-22.

30. Ting N-C, Jansen J, Nagappan J, Ishak Z, Chin CW, Tan S-G, et al. Identification of QTLS associated with callogenesis and embryogenesis in oil palm using genetic linkage maps improved with SSR markers. PLoS ONE. 2013; doi:10.1371/journal.pone.0053076
31. Katialisa K, Ithnin M, Ooi LCL, Ting NC, Musa B, Singh R. Construction of SNP- and SSR-based genetic linkage map in the oil palm backcross two $\left(\mathrm{BC}_{2}\right)$ mapping population. In Proceedings of the 2013 PIPOC International Palm oil Congress, 19-21 November 2013, Kuala Lumpur Convention Centre, Kuala Lumpur, Malaysia. p.158

32. Xu S. Theoretical basis of the Beavis effect. Genetics. 2003;165:2259-68.

33. Beavis WD. QTL analyses: power, precision, and accuracy. In: Paterson AH, editor. Molecular dissection of complex traits. New York: CRC Press; 1998. p. 145-62.

34. Frary A, Frary A, Daunay M-C, Huvenaars K, Mank R, Doğanlar S. QTL hotspots in ggplant (Solanum melongena) detected with a high resolution map and CIM analysis. Euphytica. 2014;197:211-28.

35. Burns MJ, Barnes SR, Bowman JG, Clarke MHE, Werner CP, Kearsey MJ. QTL analysis of an intervarietal set of substitution lines in Brassica napus: (i) seed oil content and fatty acid composition. Heredity. 2003;90:39-48.

36. Wassom JJ, Mikkelineni V, Bohn MO, Rocheford TR. QTL for fatty acid composition of maize kernel oil in Illinois high oil X B73 backcross-derived lines. Crop Sci. 2008;48:69-78.

37. Li L, Li H, Li Q, Yang X, Zheng D, Warburton M, et al. An 11-bp insertion in Zea mays fatb reduces the palmitic acid content of fatty acids in maize grain. PLoS ONE. 2011; doi:10.1371/journal.pone.0024699

38. Cardinal AJ, Whetten R, Wang S, Auclair J, Hyten D, Cregan P, et al. Mapping the low palmitate fap 1 mutation and validation of its effects in soybean oil and agronomic traits in three soybean populations. Theor Appl Genet. 2014;127:97-111.

39. Oboh BO, Fakorede MAB. Optimum time for yield evaluation and selection in the oil palm (Elaeis guineensis Jacq.). Oléagineux (Paris). 1989:44(11):509-13.

40. Mayes S, Jack PL, Marshall DF, Corley RHV. Construction of a RFLP genetic linkage map for oil palm (E. guineensis Jacq.). Genome. 1997;40:116-22.

41. Rajanaidu N, Rao VR. Managing plant genetic resources and the role of private and public sectors: oil palm as a model. In: Engels JMM, Rao VR, Brown AHD, Jacson MT, editors. Managing plant genetic diversity. Wallingford: CAB international; 2002. p. 425-36.

42. Melchinger AE, Friedrich Utz H, Schön CC. Quantitative trait locus (QTL) mapping using different testers and independent population samples in maize reveals low power of QTL detection and large bias in estimates of QTL effects. Genetics. 1998;149:383-403.

43. Sambanthamurthi R, Oo KC. Thioesterase activity in the oil palm (Elaeis quineensis) mesocarp. In: Quinn PJ, Harwood JL, editors. Plant lipid biochemistry, structure and utilization. London: Portland Press Ltd; 1990. p. 166-68.

44. Sambanthamurthi R, Abrizah O, Umi Salamah R. Biochemical factors that control oil composition in the oil palm. J. Oil Palm Res. (Spec Iss). 1999:24-33

45. Pirtle RM, Yoder DW, Huynh TT, Nampaisansuk M, Pirtle IL, Chapman KD. Characterization of a palmitoyl-acyl carrier protein thrioesterase (FatB 1$)$ in cotton. Plant Cell Physiol. 1999;40(2):155-63.

46. Jing F, Cantu DC, Tvaruzkova J, Chipman JP, Nikolau BJ, Yandeau-Nelson $M D$, et al. Phylogenetic and experimental characterization of an acyl-ACP thioesterase family reveals significant diversity in enzymatic specificity and activity. BMC Biochem. 2011;12:44.

47. Zheng P, Ali Babar MD, Parthasarathy S, Gibson R, Parliament K, Flook J, et al. A truncated FatB resulting from a single nucleotide insertion is responsible for reducing saturated fatty acids in maize seed oil. Theor Appl Genet. 2014;127:1537-47.

48. Dörmann P, Voelker TA, Ohlrogge JB. Accumulation of palmitate in Arabidopsis mediated by the acyl-acyl carrier protein thioesterase FATB1. Plant Physiol. 2000;123:637-43.

49. Parveez G-K-A, Abrizah O, Nurhafizah R, Bahariah B. Functional analysis of oil palm palmitoyl-ACP thioesterase (FatB) gene via down-regulation in a model plant: Arabidopsis thaliana. J Oil Palm Res. 2010;22:803-13.

50. Jones A, Davies HM, Voelker TA. Palmitoyl-acyl aarrier protein (ACP) thioesterase and the evolutidnary origin of plant acyl-ACP thioesterases. Plant Cell. 1995;7:359-71.

51. Dussert S, Guerin C, Andersson M, Joët T, Tranbarger TJ, Pizot M, et al. Comparative transcriptome analysis of three oil palm fruit and seed tissues that differ in oil content and fatty acid composition. Plant Physiol. 2013:162:1337-58.

52. Kagale S, Koh C, Nixon J, Bollina V, Clarke WE, Tuteja R, et al. The emerging biofuel crop Camelina sativa retains a highly undifferentiated hexaploid genome structure. Nat Comm. 2014;5:3706. 
53. Liang Y, Yuan Y, Liu T, Mao W, Zheng Y, Li D. Identification and computational annotation of genes differentially expressed in pulp development of Cocos nucifera L. by suppression subtractive hybridization. BMC Plant Biol. 2014;14:205.

54. Furumoto T, Yamaguchi T, Ohshima-Ichie Y, Nakamura M, Tsuchida-Iwata Y, Shimamura M, et al. A plastidial sodium-dependent pyruvate transporter. Nature. 2011;476:472-75.

55. Ichihara K, Yamane K, Hirano E. Acyl-coA synthetase in oilseeds: fatty acid structural requirements for activity and selectivity. Plant Cell Physiol. 1997;38(6):717-24.

56. Shockey JM, Fulda MS, Browse JA. Arabidopsis contains nine long-chain acyl-coenzyme a synthetase genes that participate in fatty acid and glycerolipid metabolism. Plant Physiol. 2002;129:1710-22.

57. Vanhercke T, Tahchy AE, Shrestha P, Zhou X-R, Singh SP, Petrie JR. Synergistic effect of WRI1 and DGAT1 coexpression on triacylglycerol biosynthesis in plants. FEBS Lett. 2013;587:364-69.

58. Maeo K, Tokuda T, Ayame A, Mitsui N, Kawai T, Tsukagoshi H, et al. An AP2type transcription factor, WRINKLED1, of Arabidopsis thaliana binds to the AW-box sequence conserved among proximal upstream regions of genes involved in fatty acid synthesis. Plant J. 2009;60:476-87.

59. Qu J, Ye J, Geng Y-F, Sun Y-W, Gao S-Q, Zhang B-P, et al. Dissecting functions of KATANIN and WRINKLED1 in cotton fiber development by virus-induced gene silencing. Plant Physiol. 2012;160:738-48.

60. To A, Joubès J, Barthole $G$, Lécureuil A, Scagnelli A, Jasinski S, et al. WRINKLED transcription factors orchestrate tissue-specific regulation of fatty acid biosynthesis in Arabidopsis. Plant Cell. 2012;24:5007-23.

61. Tajima D, Kaneko A, Sakamoto M, Ito Y, Hue NT, Miyazaki M, et al. Wrinkled 1 (WR/1) homologs, AP2-type transcription factors involving master regulation of seed storage oil synthesis in castor bean (Ricinus communis L.). Am J Plant Sci. 2013;4:333-39.

\section{Submit your next manuscript to BioMed Central and we will help you at every step:}

- We accept pre-submission inquiries

- Our selector tool helps you to find the most relevant journal

- We provide round the clock customer support

- Convenient online submission

- Thorough peer review

- Inclusion in PubMed and all major indexing services

- Maximum visibility for your research

Submit your manuscript at www.biomedcentral.com/submit

C Biomed Central 